\title{
Electrochemical Analysis Section:
}

Summary of Activities

July 1967 to June 1968

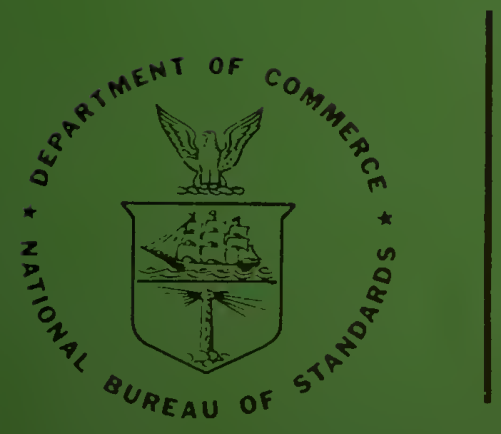

U.S. DEPARTMENT OF COMMERCE National Bureau of Standards 


\section{NATIONAL BUREAU OF STANDARDS}

The National Bureau of Standards ${ }^{1}$ was established by an act of Congress March 3, 1901. Today, in addition to serving as the Nation's central measurement laboratory, the Bureau is a principal focal point in the Federal Government for assuring maximum application of the physical and engineering sciences to the advancement of technology in industry and commerce. To this end the Bureau conducts research and provides central national services in three broad program areas and provides central national services in a fourth. These are: (1) basic measurements and standards, (2) materials measurements and standards, (3) technological measurements and standards, and (4) transfer of technology.

The Bureau comprises the Institute for Basic Standards, the Institute for Materials Research, the Institute for Applied Technology, and the Center for Radiation Research.

THE INSTITUTE FOR BASIC STANDARDS provides the central basis within the United States of a complete and consistent system of physical measurement, coordinates that system with the measurement systems of other nations, and furnishes essential services leading to accurate and uniform physical measurements throughout the Nation's scientific community, industry, and commerce. The Institute consists of an Office of Standard Reference Data and a group of divisions organized by the following areas of science and engineering:

Applied Mathematics-Electricity-Metrology-Mechanics-Heat-Atomic Physics-Cryogenics ${ }^{2}$-Radio Physics ${ }^{2}$-Radio Engineering ${ }^{2}$-Astrophysics ${ }^{2}$ - Time and Frequency. ${ }^{2}$

THE INSTITUTE FOR MATERIALS RESEARCH conducts materials research leading to methods, standards of measurement, and data needed by industry, commerce, educational institutions, and government. The Institute also provides advisory and research services to other government agencies. The Institute consists of an Office of Standard Reference Materials and a group of divisions organized by the following areas of materials research:

Analytical Chemistry-Polymers-Metallurgy — Inorganic Materials — Physical Chemistry.

THE INSTITUTE FOR APPLIED TECHNOLOGY provides for the creation of appropriate opportunities for the use and application of technology within the Federal Government and within the civilian sector of American industry. The primary functions of the Institute may be broadly classified as programs relating to technological measurements and standards and techniques for the transfer of technology. The Institute consists of a Clearinghouse for Scientific and Technical Information, ${ }^{3}$ a Center for Computer Sciences and Technology, and a group of technical divisions and offices organized by the following fields of technology:

Building Research-Electronic Instrumentation - Technical Analysis - Product

Evaluation-Invention and Innovation-Weights and Measures - Engineering Standards_Vehicle Systems Research.

THE CENTER FOR RADIATION RESEARCH engages in research, measurement, and application of radiation to the solution of Bureau mission problems and the problems of other agencies and institutions. The Center for Radiation Research consists of the following divisions:

Reactor Radiation-Linac Radiation-Applied Radiation-Nuclear Radiation.

\footnotetext{
${ }_{1}^{1}$ Hearlquarters and Laboratories at Gaithersurg. Maryland, unless otherwise noted; mailing address Washington, D. C. 20234. ${ }^{2}$ Located at Boulder, Culorado 80302.

Located at 5285 F rt Royal Road, Springfield, Virginia 22151.
} 


\title{
UNITED STATES DEPARTMENT OF COMMERCE
}

C. R. Smith, Secretary

NATIONAL BUREAU OF STANDARDS • A. V. Astin, Director

\section{NBS TECHNICAL NOTE 453 \\ ISSUED JULY 1968}

\author{
Electrochemical \\ Analysis Section: \\ Summary of Activities \\ July 1967 to June 1968
}

Edited by Roger G. Bates

Electrochemical Analysis Section

Analytical Chemistry Division

Institute for Materials Research

NBS Technical Notes are designed to supplement the Bureau's regular publications program. They provide a means for making available scientific data that are of transient or limited interest. Technical Notes may be listed or referred to in the open literature.

For sale by the Superintendent of Documents, U.S. Government Printing Office, Washington, D.C., 20402 Price 55 cents. 
The Analytical Chemistry Division was established as a separate division at the National Bureau of Standards on September 1, 1963, and became part of the Institute for Materials Research in the February 1, 1964, reorganization. It consists at present of nine sections and about 100 technical personnel encompassing some 57 different analytical competences from activation analysis and atomic absorption to vacuum fusion and $x$-ray spectroscopy. These competences, and in turn the sections which they comprise, are charged with research at the forefront of analysis as well as awareness of the practical sample, be 1 t standard reference material or service analysis. In addition 1 is their responsibility to inform others of their efforts.

Formal publication in sclentific periodicals is a highly lmportant output of our laboratorles. In addition, however, It has been our experience that informal, annual summarles of progress describing efforts of the past year can be very valuable in disseminating information about our programs. A word is perhaps in order about the philosophy of these yearly progress reports. In any research program a large amount of information is obtained and techniques developed which never find their way into the literature. This includes the "negative results" which are so disappointing and unspectacular but which can often save others considerable work. Of Importance also are the numerous small 1tems which are often explored in a few days and which are not important enough to warrant publication--yet can be of great interest and use to specialists in a given area. Finally there are the experimental techniques and procedures, the designs and modifications of equipment, etc., which often must be covered in only a line or two of a journal article. 
Thus our progress reports endeavor to present this information which we have struggled to obtain and which we feel might be of some help to others. Certain areas which It appears will not be treated fully in regular publications are considered in some detall here. Other results which are belng written up for publication in the journal literature are covered in a much more abbreviated form.

At the National Bureau of Standards publications such as these flt loglcally into the category of a Technical Note. In 1968 we plan to 1ssue these summaries for all of our sections. The following is the fourth annual report on progress of the Electrochemical Analysis Section.

W. Wayne Melnke, ChIef

Analytical Chemistry Division 
This is the fourth annual progress report of the Electrochemical Analysis Section of the Analytical Chemistry Division. It covers the fiscal year 1968, which began on July 1, 1967, and ended on June 30, 1968.

The Section concerns itself particularly with ionic processes occurring in solution, with areas of analytical measurement where ionic equilibria play a part, and with the explanation of solution behavior in terms of the interactions of ionic solutes with solvent molecules. The special interests of the members of the Section lie for the most part in solution electrochemistry, electrochemical thermodynamics, and ionic transport phenomena. In the context of modern analytical chemistry, their competences bear most directly on potentiometry, electrometric titrations, and conductometric analysis. In line with a uniform policy of the Division, the Section's programs have both research and sample aspects. During the fiscal year just ending, the total effort of the section was divided almost equally between research and the development of standard reference materials.

The permanent staff of the Section was further reduced during the year with the resignations in July of Hannah B. Hetzer and Dr. R. A. Robinson. Dr. Robinson had served as assistant chief of the section for six years, and with his departure the project on isopiestic vapor pressure measurements was terminated. During the summer months of 1967 , however, the staff of the Section was augmented by the presence of Dr. Karl H. Pool of the Department of Chemistry, Washington State University at Pullman, and of Edgar S. Etz, a graduate student at Clarkson College of Technology. 
Dr. Donald Rosenthal, professor of chemistry at Clarkson, was named a consultant to the section. During their stay, Dr. Pool and Mr. Etz made material contributions to our studies of acid-base phenomena in mixed solvents. The arrival in October of Dr. Marinus Alfenaar of the University of Utrecht, Holland, to flll a one-year appointment, enabled us to initiate a project on standards for ion-selective electrodes. This work was continued throughout the fiscal year with the welcome financlal support of the Foxboro Company, of Foxboro, Massachusetts.

With a permanent staff of only four, it has obviously been impossible to conduct a broad program in the electrochemistry of solutions. For this reason, the activity of the past year has been limited to emf studies and conductance measurements. Unlike the formal publications that appear in the scientific journals, this report summarizes the total program of the Section, incomplete studies as well as finished work, and stresses its relationship to the missions of the Division and Institute.

In order to specify adequately the procedures, it has been necessary occasionally to identify commercial materials and equipment in this report. In no case does such identiflcation imply recommendation or endorsement by the National Bureau of standards, nor does it imply that the material or equipment identified is necessarily the best available for the purpose.

The assistance of Mrs. Rosemary Maddock, Mrs. Marguerite Raudenbush, and Robert $J$. Boreni in the preparation of this report is gratefully acknowledged.

Roger G. Bates, Chief Electrochemical Analysis Section

Washington, D.C. June 30, 1968 
1. FACILITIES AND EQUIPMENT . . . . . . • . 1

2. ACIDITY MEASUREMENTS .............. 4 Concepts and Program ............ . . 4 Surface Potentials and Single Ion Activities. 5 Objectives ............ . 5 Instrumentation . . . . . . . . . 7 New pH Standards . . . . . . . . . 8

Potassium Dihydrogen Citrate . . . . 9

Carbonate Buffer Solution . . . . . 10

Internal Consistency . . . . . . . 14 pD Standardization . . . . . . . . . 15

Response of the Glass Electrode in Deuterium Oxide . . . . . . . 15

Standards for pD Measurement . . . . 15

Potassium Dihydrogen Citrate . . . 16

Carbonate Buffer . . . . . . 17

Internal Consistency of th.

pD Scale......... . . 19

Certification of Standard Reference Materials . . . . . . . . 22 Measurement of Acldity in Sea Water . . . 24

3. SOLVENT EFFECTS ON ELECTROLYTE PROCESSES • • 25 Ion-Solvent Interactions . . . . . . 25 Water structure and Medium Effects in Mixed Aqueous Solvents....... 26 Structural Effects in N-MethylpropionamideWater Mixtures .......... . 30 Emf Studies in Methanol-Formamide Mixtures . . 32 Emf Studies in Methanol-Propylene Carbonate Mixtures Emf Studies in $\mathrm{N}$-Methylpropionamide-Hydrocarbon Mixtures

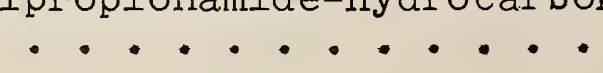


4. STANDARDIZATION OF ION-SELECTIVE ELECTRODES • . 37 General Princlples . . . . . . . . 37

Definition of Activity Coefficients . . 38

Liquid-Junction Potentials ...... . 39

Electrode Response ......... . 40

Measurement of Chloride Ion Activity ..... 41

Measurement of Sodium Ion Activity . . . . 43

5. EQUIITBRIUM DATA FOR IONIC SYSTEMS . . . . 46

Thermodynamics of Hydrochloric Acid

in 92.41 Wt. Percent Ethanol ....... 46

Second Dissociation Constant of Carbonic Acld

in Deuterium Oxide ......... 50

Properties of Acids and Bases in Hydrogen-

Bonded Mixed Solvents . . . . . . . 53

6. CONDUCTANCE AND TRANSPORT BEHAVIOR OF

EIECTROIYTES

Oceanographic Conductance Standards . . . . 57

Apparatus . . . . . . . . . . 57

Characteristics of "Azulene Periodate" . . . 60

Hydrodynamic Properties of Ions . . . . . . 61

7. PREPARATION AND PROPERTIES OF SOLVENTS . . . 64

Propylene Carbonate . . . . . . . . . 64

Cryoscopic Behavior of N-Methylpropionamide . . 64

8. FOREIGN-CURRENCY PROGRAMS . . . . . . 66

9. REVIEWS, CONEERENCES, AND COMMITTEE ACTIVITY. . 67

10. IMPACT OF SECTION'S ACTIVITIES . . . . . . 68

11. PERSONNEI ............... 69

12. COMMITTEE MEMBERSHIPS . . . . . . . . 70

13. PUBLICATIONS AND MANUSCRIPTS,

JUIY 1967 TO JUNE 1968 . . . . . . . 71

14. TALKS, JULY 1967 TO JUNE 1968...... . 73

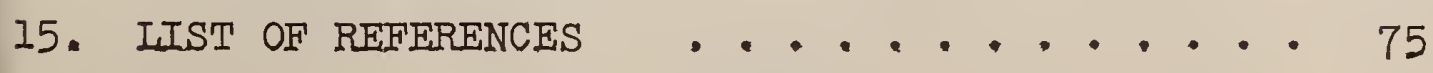


FIGURE NO.

PAGE

1. Laboratory for the certification of pH standards. . . . . . . . . .

2. Equipment for dielectric constant measurements. . . . . . . . . . 2

3. Cell for the measurement of the surface potentials of electrolyte solutions . . . 7

4. $\mathrm{pH}(\mathrm{S})$ as a function of temperature. . . . 12

5. Values of $\mathrm{pD}(\mathrm{S})$ for two primary standards in deuterium oxide as a function of temperature . . . . . . . 20

6. Solvent effect on the dissociation of p-nitroanilinium ion in methanol-water solvents compared with that in methanolpropylene glycol solvents . . . . . 28

7. Molar volume of transfer from pure organic liquid to aqueous solution at $30^{\circ} \mathrm{C}$...

8. Pseudo-Kirkwood correlation parameters for binary mixtures of water and organic liquids . . . . . . . . . . 32

9. Response of a chloride ion-selective electrode in solutions of sodium chloride at $25{ }^{\circ} \mathrm{C}$

10. Response of a chloride ion-selective electrode in equimolal mixtures of sodium chloride and potassium nitrate at $25^{\circ} \mathrm{C}$.

11. Equipment for emf measurements with ion-selective electrodes........

12. Variation of $\log \gamma_{+}$for hydrochloric acid with the square root of the molality in 92.41 wt. percent ethanol compared with that in water and in $50 \mathrm{wt}$. percent ethanol

13. Determination of $\mathrm{pK}_{2}$ for deuterocarbonic

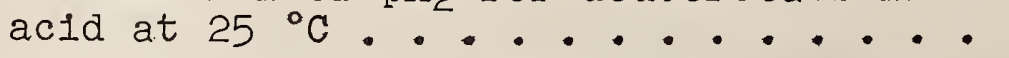

14. Standard thermodynamic functions for the transfer of hydrochloric acid from water to ethylene glycol-water solvents at $25^{\circ} \mathrm{C}$ 
FIGURE NO.

PAGE

15. Standard thermodynamic functions for the transfer of acetic acid from water to ethanol-water solvents at $25{ }^{\circ} \mathrm{C}$. . . 56

16. Janz-McIntyre conductivity bridge . . . 58

17. Demountable conductivity cells . . . . 59

LIST OF TABLES

TABIE NO.

PAGE

1. Standard reference values of $\mathrm{pH}(\mathrm{S})$ for $0.05 \mathrm{~m}$ potassium dihydrogen citrate . .

2. Standard reference values of $\mathrm{pH}(\mathrm{S})$ for the solution 0.025 mola.l with respect to both sodium bicarbonate and sodium carbonate . . . . . . . . . . . 11

3. Homogeneity tests on carbonate salts. Acidity functions for solutions of the composition: $\mathrm{NaHCO}_{3}(0.025 \mathrm{~m})$, $\mathrm{Na} 2 \mathrm{CO}_{3}(0.025 \mathrm{~m}), \mathrm{KCI}(0.01 \mathrm{~m})$ at $25^{\circ} \mathrm{C} \cdot . \cdot 13$

4. Intercomparison of new reference buffers with the phosphate buffer standard from 5 to $45{ }^{\circ} \mathrm{C}$. . . . . . . 14

5. Standard reference values of pa for $0.05 \mathrm{~m}$ $\mathrm{KD}_{2}$ citrate in deuterium oxide . . . . 17

6. Standard reference values of pap for the solution 0.025 molal with respect to both $\mathrm{NaDCO}_{3}$ and $\mathrm{Na}_{2} \mathrm{CO}_{3}$ in deuterium oxide

7. Intercomparison of reference buffers in deuterium oxide at $25{ }^{\circ} \mathrm{C}$ measured against the phosphate buffer standard $[\mathrm{pD}(\mathrm{S})=7.429]$. . . . . . . . . 21

8. Emf of the cell: $\mathrm{Pt} ; \mathrm{H}_{2}, \mathrm{HCI}(0.02 \mathrm{~m})$ in solvent $a$ or $\mathrm{b}, \mathrm{AgCl} ; \mathrm{Ag}$ at $25{ }^{\circ} \mathrm{C}$ (in volts).

9. Experimental determination of $-\log \gamma_{\mathrm{Na}}+$ in solutions of sodium salts at different Ionic strengths from measurements with a. sodium-selective NAS 11-18 glass electrode at 25 
TABLE NO.

10. Determination of the standard emf $\left(\mathrm{E}^{\circ}\right)$

for the cell: Pt; $\mathrm{H}_{2}, \mathrm{HCI}(\mathrm{m})$ in

92.41 wt. \% ethanol, $\mathrm{AgCI} \mathrm{Ag}$ at

5,25 , and $50^{\circ} \mathrm{C}$

11. Comparison of $\bar{I}_{2}$ and $\bar{J}_{2}$ for hydrochloric

acid (0.1 molal) in water and in 92.41

wt. percent ethanol at $25{ }^{\circ} \mathrm{C}$...... 50

12. Dissociation of the deuterocarbonate ion

5 to $50^{\circ} \mathrm{C}$. $\mathrm{DCO}_{3}^{-}$in deuterium oxide from

13. Freezing point and cryoscopic constant of

N-methylpropionamide ........ 65 
ELECTROCHEMICAL ANAIYSIS SECTION: SUMMARY OF ACTIVITIES, JULY 1967 TO JUNE 1968

Edited by Roger G. Bates

\section{ABSTRACT}

This survey of the activities of the Electrochemical Analysis Section, Analytical Chemistry Division, covers the period July 1967 to June 1968. An attempt is made to summarize a year's progress on the technical projects of the Section in such a way as to stress the program and capabilities of the organizational unit as a whole. Brief summaries of several lines of work under way are given. The review describes briefly new equipment and facilities acquired during the year. A major effort devoted to acidity measurements has led to new $\mathrm{pH}$ standards and new reference solutions for pD in heavy water. Solvent effects on acidbase phenomena in mixed solvents have shed some light on the factors, including solvent structure, governing lon-solvent interactions. A start was made on the study of ion-specific electrodes and the establishment of standard scales for ionic activity. Equilibrium data for hydrochloric acid in 92.41 wt. percent ethanol and for the 1onization of carbonic acid in heavy water have been obtained. The establishment of conductance standards for oceanographic research was begun. The survey concludes with lists of the members of the Section staff, publications and manuscripts produced during the year, talks given by the staff, and committee assignments.

\section{Key Words}

Acldity, Analysis, Conductance measurements, Electrochemical analysis, Electrochemistry of solutions, Ionic activity, Ion-selective electrodes, pD measurements, pH measurements, Medium effects, Solvent effects 

Excellent facilities for the Section's programs are provided on the second floor of the Chemistry Building at the Galthersburg site of the National Bureau of Standards. These laboratories have now been occupled for more than two years, and the inevitable minor changes and adjustments necessary to adapt a general-purpose laboratory to our special needs have been completed.

The space devoted to research consists at present of a conductance laboratory and four well-equipped emf laboratories. The instrumentation room has been outfitted to accommodate the recording spectrophotometer, the instrument for measuring dielectric constants of solvents, the automatic titrator, microbalance, and several pH meters. One of the emf laboratories is shown in figure 1 , and the dielectric constant instrument is shown in figure 2 .

Two 1tems of capital equipment were acquired during the year. One was a vibrating-reed electrometer needed for the measurement of the potentials of glass electrodes and ion-selective electrodes. A commercial impedance comparator that utilizes closely matched transformer ratio arms was also purchased. This instrument, which indicates the difference between two impedances with a spec1fied accuracy of $30 \mathrm{ppm}$, is especially useful for precise measurements of the conductance of highly conducting solutions.

One of the four emf laboratories is now devoted to studies of aqueous solutions and to certification of $\mathrm{pH}$ standards, although the cells and measuring equipment are so designed and arranged that studies of nonaqueous and mixed solvents can be conducted when time permits. A second emf laboratory was devoted almost exclusively to work in 


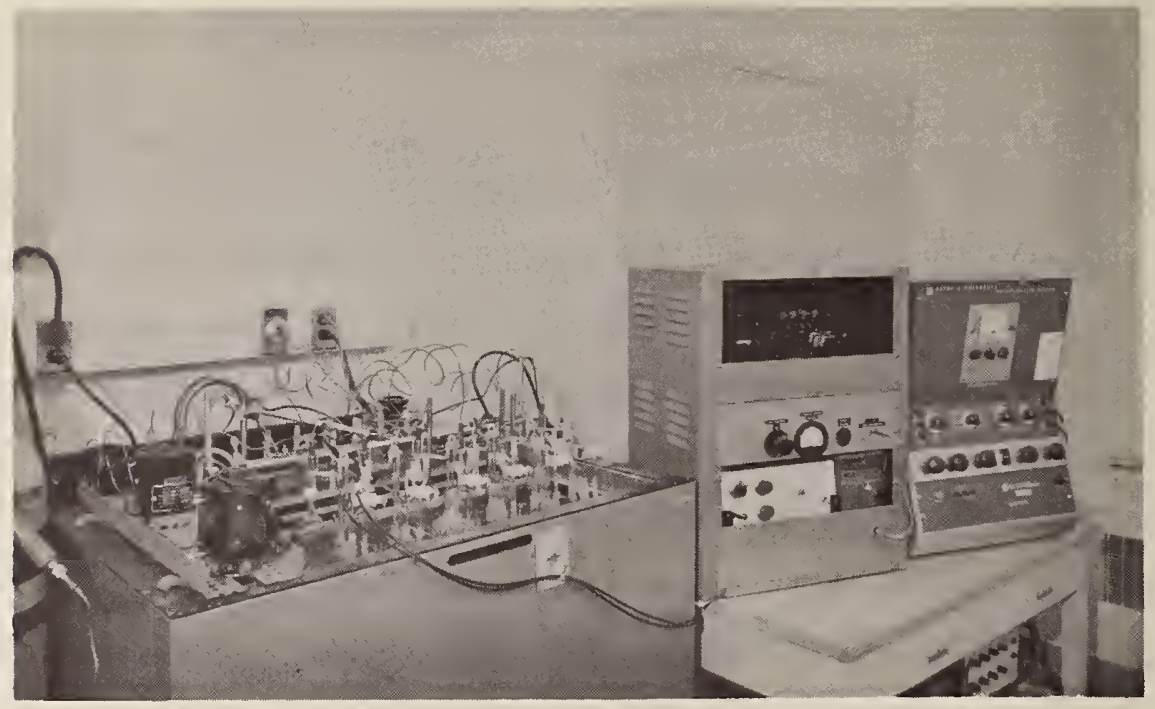

Figure 1. Laboratory for the certification of $\mathrm{pH}$ standards.

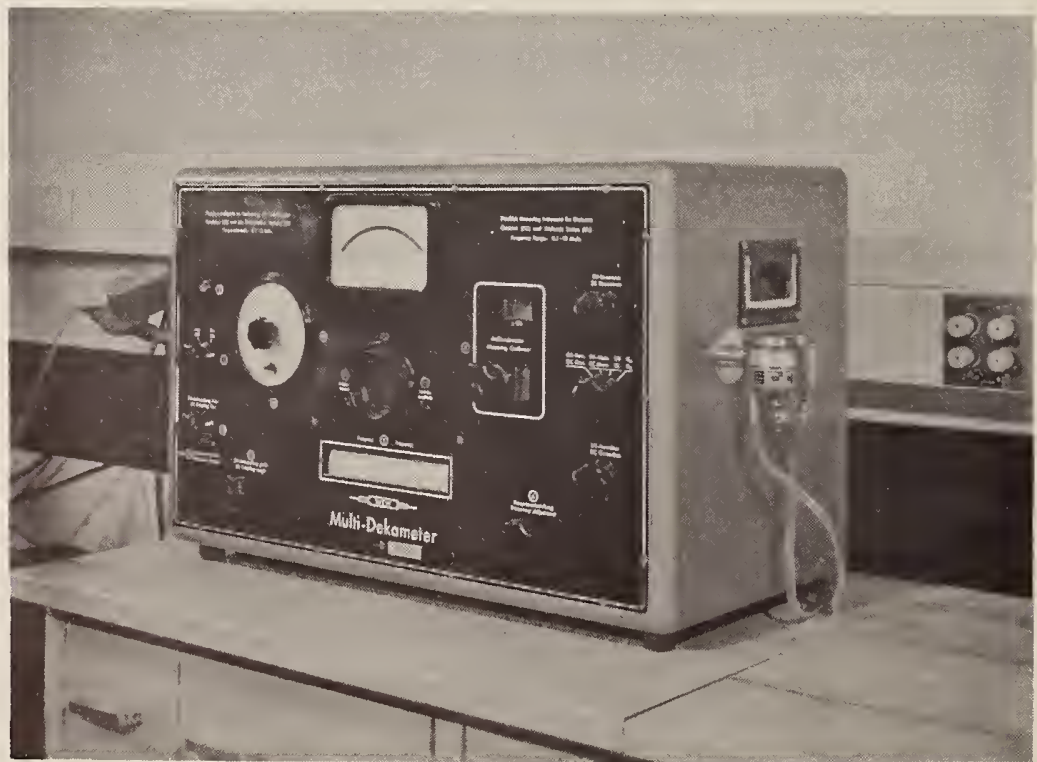

Figure 2. Equipment for dielectric constant measurements. 
deuterium oxide with deuterium gas electrodes and glass electrodes during the current year. Investigations of ion-selective electrodes were conducted in a third, while a fourth, in use only during the summer months, was given over to studies of acid-base processes in nonaqueous mixed solvents.

This installation is sufficiently large to warrant the inclusion of an automatic data read-out center capable of recording automatically and simultaneously the emf of all the cells under study in each of the laboratories. A multichannel digital voltmeter with an accuracy of $10 \mu \mathrm{V}$ is needed. It would be coupled to a print-out unit from which a record of all the emf data could be obtained and, when desired, a tape could also be produced for computer analysis. Measurements of all cells at desired intervals could be programmed in advance.

Because of staff limitations, it has not yet been posilble to initiate work on the accurate measurement of $\mathrm{pH}$ at high temperatures and pressures or to supplement our present capability with calorimetric studies of ionic processes in solution. When these types of work are begun, additional facilities and equipment will be needed.

(R. G. Bates) 


\section{ACIDITY MEASUREMENTS}

A. Concepts and Program

The measurement of acidity continues to be one of the major concerns of the section. The concepts and approaches of our efforts in this area were set forth in the annual progress reports for 1966 [1] and 1967 [2].

The NBS pH scale is fixed by a series of standard reference solutions chosen to cover uniformly that region of the scale in which the emf of the pH cell is a linear function of the pH of the solution in which the electrodes are immersed. Corrections are made, if necessary, for imperfections in the response of the glass electrode. Unlike the $\mathrm{pH}$ scale of the British Standards Institution [3], which recognizes only a single primary standard, the NBS approach permits a series of primary reference solutions. The search for new and better standards is going on continually. A new standard may be selected because it extends the useful range of the standard scale or because it shows a stability superior to those of existing standards in its $\mathrm{pH}$ range.

During the past year, work was continued and extended on the measurement of acidity in deuterium oxide (heavy water). The $\mathrm{pD}$ scale in heavy water bears the same fundamental relationship to the deuterium gas electrode that the pH scale bears to the hydrogen gas electrode. Basically, the phenomena which are regarded as a manifestation of "acidity" in these two media can be attributed to two distinctly different entities, namely the deuterium ion and the hydrogen ion. For this reason, the pD scale is not related to the $\mathrm{pH}$ scale. The same methods can nonetheless be utilized for establishing acidity standards in deuterium oxide as have been used to set up $\mathrm{pH}$ standards in ordinary water. During the past year an operational pD scale fixed by three standard reference solutions has been established. 
In amphiprotic (water-like) solvents of moderate to high dielectric constant it is useful to correlate acidbase behavior with the concentration or activity of the acidic elements hydrogen ion and deuterium ion. This approach is a worthwhlle one not only for water but also for aqueous mixed solvents and for some nonaqueous media. The extension of the $\mathrm{pH}$ concept to media other than pure water has recelved considerable attention in the Section during the past few years. At the time of 1ssuance of the new $\mathrm{pH}$ and $\mathrm{pD}$ standards, a review article on this subject was published [4].

A truly general scale of acidity as envisioned by Bronsted [5] w11l become a reality only when an acceptable scale of lonic medium effects or ionic transfer free energies has been determined or defined by convention [6]. Although the medium effect for a single lonic species cannot be derived by thermodynamic means, there is a growing belief that it may often be a real and useful physical concept. A valid procedure for separating medium effects for electrically neutral combinations of lons into their cationic and anionic constituent parts is still being sought. These efforts continue to claim the interest and attention of members of the section.

(R. G. Bates)

B. Surface Potentials and Single Ion Activities

1. Objectives

It has been shown that single ion activities play an important role in the establishment of useful pH scales [7]. Nevertheless, single ion activities cannot be measured. They have an arbitrary meaning derived malniy from a convention which regards the inner potential (the Galvani potential $\varphi$ ) as a macroscopic property of the medium. 
Thus, no net electrostatic work is performed when an electrically neutral combination of ions is removed from the medium, and the total work can be defined as the sum of the chemical potentials of the ions.

The activity of an ion $i$ is formally related to the chemical potential $\mu_{i}$ by

$$
R T \ln a_{i}=\mu_{i}-\mu_{i}^{0}
$$

where $\mu_{i}^{0}$ is the chemical potential in a selected standard reference state. Heretofore, all attempts to estimate $\mu_{i}$ for single ionic species have been based on an arbitrary splitting of chemical potentials for electrically neutral combinations of ions or on similar nonthermodynamic procedures. In principle, however, it is possible to measure the electrochemical potential $\bar{\mu}_{1}=\mu_{1}+F_{\varphi}$ of a single ionic species. Then if $\varphi$ is known or can be estimated, one can obtain an estimate of $\mu_{1}$. When $\varphi$ is small, a rather inaccurate estimate of its value is sufficient to obtain relatively accurate values of $\mu_{i}$.

It is the purpose of the present study to obtain more information on the Galvani potential $\varphi$. For this, measurements will be made on cells of the type

$$
\mathrm{Ag} ; \mathrm{AgCl}, \operatorname{MCl}\left(\mathrm{m}_{1}\right) \text { in } \mathrm{H}_{2} \mathrm{O}|\operatorname{air}| \mathrm{MCl}\left(\mathrm{m}_{2}\right) \text { in } \mathrm{H}_{2} \mathrm{O}, \mathrm{AgCl} ; \mathrm{Ag}
$$

with different cations $\mathrm{M}^{+}$and different ionic strengths. Starting at very low concentrations, where it can be assumed that single ion activities for different univalent ions do not differ appreciably, it is hoped to find some relation to describe the surface potential at the solution-gas interface. This relation, we hope, can be extended to higher concentrations so that an estimate of $\mu_{i}$ in that range will also become possible. 


\section{Instrumentation}

For the solution of this problem, emf measurements have to be performed with high precision ( $0.1 \mathrm{mV}$ or better) on cells with very high impedance. For this purpose, we have at our disposal a vibrating-reed electrometer. It is expected that the measurements to be performed will fall just within the capability of this instrument. The cell that has been constructed for this study is shown in figure 3. The design is that of Randles [8].

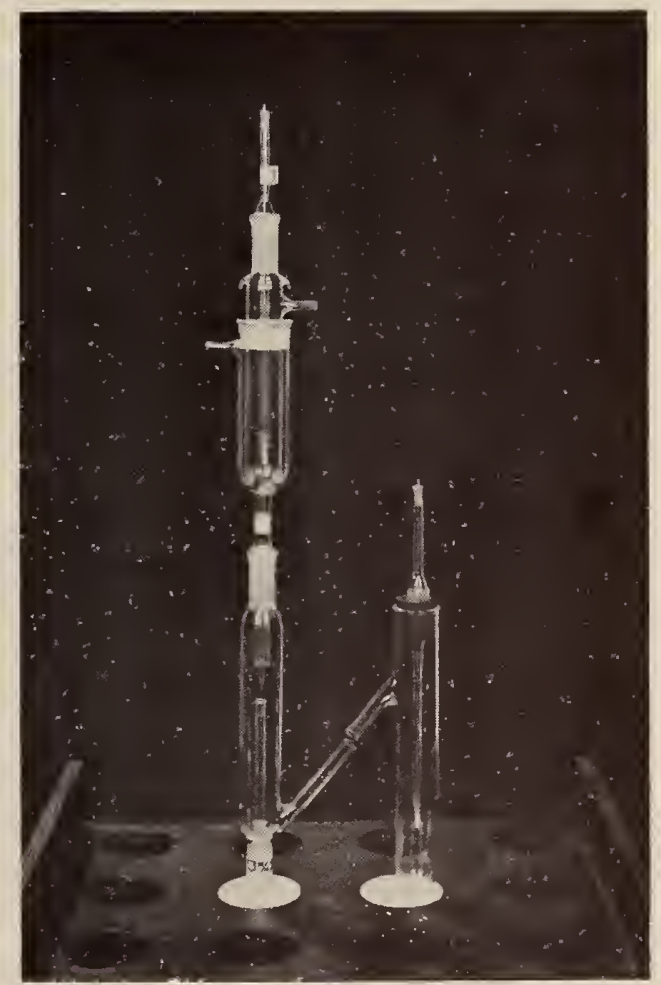

Figure 3. Cell for the measurement of the surface potentials of electrolyte solutions.

(M. Alfenaar) 
C. New pH Standards

During the past year, research on two pH standard solutions proposed as new reference points on the NBS standard pH scale has been completed. The solutions are 0.05 molal potassium dihydrogen citrate and a mixture of sodium bicarbonate and sodium carbonate, each 0.025 molal.

The precise emf measurements leading to the assignment of $\mathrm{pH}(\mathrm{S})$ values to these reference solutions over the temperature range 0 to $50{ }^{\circ} \mathrm{C}$ were completed. The procedures used for this assignment have already been adequately described in previous reports $[1]$,$] . An over-all view of$ the equipment used is given in figure 1.

A few noteworthy alterations of the usual procedure were made. The calculation of the ionic strengths of the buffer solutions, for example, was adapted to an iterative computer technique which utilized all of the appropriate dissociation constants for the acidic groups governing the $\mathrm{pH}$ of the buffer, namely the three dissociation steps of citric acid and the two steps of carbonic acid.

Computer techniques were applied extensively in the analysis of the emf data. In fact, by the use of several computer programs it is now possible to start with the measured emf and the corresponding barometric pressure and arrive at the $\mathrm{pa}_{\mathrm{H}}$ value of the solution entirely by computer. The procedure enables one not only to apply precise corrections for barometric pressure, etc., to each individual data point but also minimizes human computational errors. Each of the three applicable programs produces a tape of results which can then be fed directly into the subsequent program or modified to include only selected data, if desired. 


\section{Potassium Dihydrogen Citrate}

Inasmuch as each of the present, standards which fix the lower end of the $\mathrm{pH}$ scale has certain disadvantages under various conditions, potassium dihydrogen citrate was chosen as an addition to the list of primary $\mathrm{pH}$ standards. The 0.05 molal solution has a $\mathrm{pH}(\mathrm{S})$ of 3.776 at $25{ }^{\circ} \mathrm{C}$.

Two of the present reference solutions have $\mathrm{pH}(\mathrm{S})$ values in the same region as does this citrate solution. They are the tartrate and phthalate solutions. However, the saturated solution of potassium hydrogen tartrate $\left[\mathrm{pH}(\mathrm{S})=3.557\right.$ at $\left.25^{\circ} \mathrm{C}\right]$ is subject to mold growth after a few days, and the pH may change by as much as 0.1 unit. Furthermore, the widely-used phthalate reference solution absorbs strongly in the ultraviolet region of the spectrum; hence, this solution is of limited application in many spectrophotometric procedures for the study of dissociation constants and other acid-base interactions.

The emf measurements on the solution of potassium dihydrogen citrate were completed and $\mathrm{pH}(S)$ values assigned by the usual methods. The $\mathrm{pH}(\mathrm{S})$ at 11 temperatures from 0 to $50{ }^{\circ} \mathrm{C}$ is listed in table 1 . A large lot of the salt has been ordered and w111 be tested and certified upon receipt. It goes without saying that minor variations in the $\mathrm{pH}(\mathrm{S})$ of different lots may occur, but these are not expected to exceed a few thousandths of a unit.

The standard solution of potassium dihydrogen citrate is easily prepared by weighing a single salt. Furthermore, the citrate salt can be obtained readily in highly pure form. Its usefulness for spectrophotometric measurements in the ultraviolet and visible regions and its high stability both in the solid form and in aqueous solutions in contact with the hydrogen electrode recommend it as an additional standard reference material for pH measurements. 
Table 1. Standard reference values of $\mathrm{pH}(\mathrm{S})$ for $0.05 \mathrm{~m}$ potassium dihydrogen citrate.

\begin{tabular}{rlll}
$t,{ }^{\circ} \mathrm{C}$ & $\mathrm{pH}(\mathrm{S})$ & $t,{ }^{\circ} \mathrm{C}$ & $\mathrm{pH}(\mathrm{S})$ \\
\hline 0 & 3.863 & 30 & 3.766 \\
5 & 3.840 & 35 & 3.759 \\
10 & 3.820 & 40 & 3.753 \\
15 & 3.802 & 45 & 3.750 \\
20 & 3.788 & 50 & 3.749 \\
25 & 3.776 & & \\
\hline
\end{tabular}

2. Carbonate Buffer Solution

The addition of the carbonate buffer solution, $0.025 \mathrm{~m}$ in both sodium bicarbonate and sodium carbonate, to the list of $\mathrm{pH}$ standards likewise offers several advantages. This reference solution extends the $\mathrm{pH}$ range beyond $\mathrm{pH} 10$ at $25{ }^{\circ} \mathrm{C}$, into a region where the uncertainties in the response of glass electrodes often become large. The $\mathrm{pH}(\mathrm{S})$ of the carbonate buffer is 10.012 at $25^{\circ} \mathrm{C}$. The materials from which the solution is prepared are obtainable in high purity and are very stable when kept dry. On the other hand, the borax used for the present standard of highest pH ( 9.180 at $25{ }^{\circ} \mathrm{C}$ ) may lose a part of its water of crystallization during prolonged storage. Furthermore, the ionic strength of the borax standard is not as well defined as might be desired, due to a tendency of boric acid to polymerize in solution. For this reason, the concentration of borax in the reference solution has to be kept low, with a consequent sacrifice of buffer capacity. The carbonate buffer does not suffer from this difficulty. 
The emf measurements needed to assign conventional $\mathrm{pa}_{\mathrm{H}}$ values to the carbonate standard have been completed. These values, which are identified with $\mathrm{pH}(\mathrm{S})$ in the operational definition of $\mathrm{pH}$, are listed in table 2. The variation of $\mathrm{pH}(\mathrm{S})$ for the citrate and carbonate standards with changes of temperature is illustrated in figure 4.

Table 2. Standard reference values of $\mathrm{pH}(\mathrm{S})$ for the solution 0.025 molal with respect to both sodium bicarbonate and sodium carbonate.
$t,{ }^{\circ} \mathrm{C}$
$\mathrm{pH}(\mathrm{S})$
t, ${ }^{\circ} \mathrm{C}$
$\mathrm{pH}(\mathrm{S})$

$\begin{array}{rlll}0 & 10.317 & 30 & 9.967 \\ 5 & 10.245 & 35 & 9.926 \\ 10 & 10.179 & 40 & 9.889 \\ 15 & 10.118 & 45 & 9.857 \\ 20 & 10.062 & 50 & 9.828 \\ 25 & 10.012 & & \end{array}$

In making the measurements, it was found necessary to purge the water with $\mathrm{CO}_{2}$-free air or nitrogen, or by boiling, in order to remove carbon dioxide prior to preparing the solutions. It was also necessary to protect the solutions from atmospheric carbon dioxide after preparation. In addition, best results were obtained when the flow of hydrogen through the cells was interrupted during the night, in order to minimize loss of carbon dioxide from the cell solutions as a result of the continued bubbling of the hydrogen over long periods of time. 


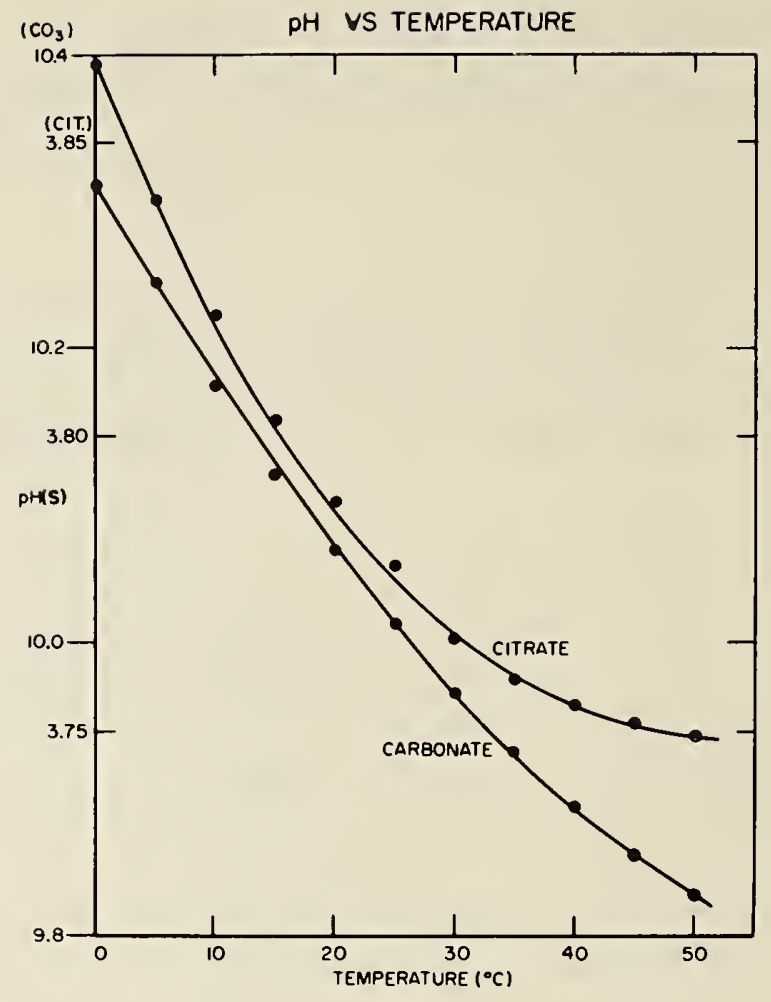

Figure 4. $\mathrm{pH}(\mathrm{S})$ as a function of temperature.

The assay of the carbonate salts was made by weight titration with a hydrochloric acid solution that had been standardized by the gravimetric silver chloride procedure. The sample was acidified with an excess of the acid, boiled under reflux, and back-titrated with a solution of sodium hydroxide that had been standardized by titration to the same end point ( $\mathrm{pH} 7$ ) with the standard solution of hydrochloric acid. 
New lots of sodium bicarbonate and sodium carbonate have been acquired. They have been assayed and tested for homogeneity and, having been found acceptable, were certified for issuance as Standard Reference Materials for $\mathrm{pH}$ measurement. The homogeneity of the lots was demonstrated by a comparison of the acidity functions $\mathrm{p}\left(\mathrm{a}_{\mathrm{H}} \gamma_{\mathrm{Cl}}\right)$ for solutions of the composition; $\mathrm{NaHCO}_{3}(0.025 \mathrm{~m}), \mathrm{Na}_{2} \mathrm{CO}_{3}(0.025 \mathrm{~m})$, $\mathrm{KCl}(0.0 \mathrm{~lm})$, prepared with different carbonate samples. The salts used were removed from the five different containers in which each of the salts was supplied. In the first run of six cells, a composite sample of sodium carbonate was used throughout, with six different samples of the bicarbonate, including a composite sample. Five of the samples of the bicarbonate were withdrawn from the five different containers; equal portions of all five were mixed to form the composite sample. In the second run, the composite sample of bicarbonate was used in each of the six cells, together with six different samples of sodium carbonate (including the composite sample). The results of the homogeneity tests are shown in table 3 .

Table 3. Homogeneity tests on carbonate salts. Acidity functions for solutions of the composition: $\mathrm{NaHCO}_{3}(0.025 \mathrm{~m}), \mathrm{Na}_{2} \mathrm{CO}_{3}(0.025 \mathrm{~m}), \mathrm{KCl}(0.0 \mathrm{~m})$ at $25{ }^{\circ} \mathrm{C}$ Sample No.

$\mathrm{p}\left(\mathrm{a}_{\mathrm{H}} \gamma_{\mathrm{CI}}\right)$ Run 1

10.117

10.121

10.117

10.117

10.117

10.118
$\mathrm{p}\left(\mathrm{a}_{\mathrm{H}} \gamma_{\mathrm{CI}}\right)$ Run 2
1

2

3

4

5

6
10.117

10.116

10.116

10.118

10.115 
3. Internal Consistency

The several primary standards that fix the NBS standard pH scale must display a satisfactory consistency when intercompared in the $\mathrm{pH}$ meter with liquid junction. Otherwise, experimental pH values for "unknown" solutions will depend on the reference solution chosen to standardize the measuring instrument. No exact consistency can be expected, however, when a liquid-junction potential is involved, as the standard solutions have different ionic strengths and necessarily contain different types of ions whose mobilities are not the same.

The new citrate and carbonate standards were compared with the equimolal phosphate standard buffer solution $\left[\mathrm{pH}(\mathrm{S})=6.865\right.$ at $\left.25^{\circ} \mathrm{C}\right]$ in a cell in which two hydrogen electrode compartments were separated by a bridge of saturated potassium chloride solution [9]. The results given in table 4 show that the pH indicated by the cell with liquid junction is higher than the assigned $\mathrm{pH}(\mathrm{S})$ for the citrate solution and lower than that assigned to the carbonate solution. The differences are less than 0.011 unit between 5 and $45^{\circ} \mathrm{C}$.

Table 4. Intercomparison of new reference buffers with the phosphate buffer standard from 5 to $45^{\circ} \mathrm{C}$.

$$
\begin{array}{lll}
t,{ }^{\circ} \mathrm{C} & \mathrm{pH}(\mathrm{obs} .)-\mathrm{pH}(\mathrm{S}) & \mathrm{pH}(\mathrm{obs} .)-\mathrm{pH}(\mathrm{S}) \\
& \text { Citrate soln. } & \text { Carbonate soln. }
\end{array}
$$

$\begin{array}{rlc}5 & 0.011 & - \\ 10 & 0.010 & -0.011 \\ 25 & 0.007 & -0.010 \\ 45 & 0.008 & -0.007\end{array}$


D. pD Standardization

1. Response of the Glass Electrode in Deuterium Oxide

The studies of the response of the glass electrode in heavy water described in the last report have been published during the year [10], giving firm evidence that this electrode, when suitably conditioned, responds to deuterium ions in heavy water as well as to hydrogen ions in ordinary water. If one uses a glass-calomel pH assembly standardized with a reference solution made up in ordinary water, an empirical correction factor of 0.45 unit (molal scale) for the pD range 2 to 9 must be added to the $\mathrm{pH}$ meter reading

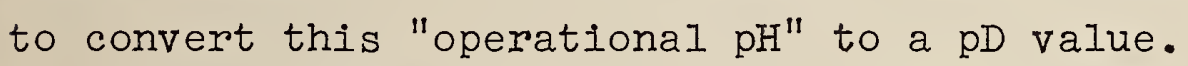

This correction need not be applied if the pH meter is standardized with a reference buffer solution in heavy water to which a $\mathrm{pD}(\mathrm{S})$ value has been assigned. Measurements with nine buffer solutions in heavy water indicate that no correction factor is necessary when a buffer mixture containing $\mathrm{KD}_{2} \mathrm{PO}_{4}$ and $\mathrm{Na}_{2} \mathrm{DPO}_{4}$ (each 0.025 molal) in heavy water is used to standardize the measuring equipment. The differences between the operational pD values and the assigned $\mathrm{pa}_{\mathrm{D}}$ values of these nine buffer solutions were negligible.

2. Standards for $\mathrm{pD}$ Measurement

As the result of earlier work in the section, $\mathrm{pD}(\mathrm{S})$ values were assigned to two solutions suitable as reference buffer solutions for $\mathrm{pD}$ measurements in heavy water $[11,12]$. The two buffer solutions were 1) a mixture of potassium dideuterium phosphate and disodium deuterium phosphate (each $0.025 \mathrm{~m}$ ) and 2) a mixture of acetic acid and sodium acetate (each $0.05 \mathrm{~m}$ ). These solutions have $\mathrm{pD}(\mathrm{S})$ values of 7.429 and 5.230, respectively, at $25{ }^{\circ} \mathrm{C}$. The proper behavior of glass electrodes in heavy water has indeed been affirmed, but, since the response of individual electrodes is not constant over the entire useful pD range, two new additional primary standards have been proposed to fix the 
practical pD scale. The new buffer materials are potassium dideuterium citrate $(0.05 \mathrm{~m})$ and a mixture of sodium deuterium carbonate and sodium carbonate (each $0.025 \mathrm{~m}$ ).

a. Potassium Dihydrogen Citrate

This particular buffer material was selected as one of the new primary reference standards for two reasons: first, because of the low pD value of 1 ts $0.05 \mathrm{~m}$ solution ( 4.29 at $25{ }^{\circ} \mathrm{C}$ ), and second, because of the relative ease with which its solutions can be prepared. Only one solid material has to be weighed, thus making this buffer preferable to the acetate buffer as a reference solution.

The preparation and purification of potassium dihydrogen citrate were described in the last report [2]. The standard values of $\mathrm{pa}_{\mathrm{D}}$ were determined by a procedure which follows closely the method for establishing primary $\mathrm{pH}$ standards in ordinary water. The emf of the cell

$$
\text { Pt; } \mathrm{D}_{2}(\mathrm{~g}), \mathrm{KD}_{2} \mathrm{Clt}(0.05 \mathrm{~m}), \mathrm{KCl}\left(\mathrm{m}_{2}\right) \text { in } \mathrm{D}_{2} \mathrm{O}, \mathrm{AgCl} ; \mathrm{Ag}
$$

was measured for buffer solutions containing three different molalities of potassium chloride $\left(m_{2}=0.005,0.01\right.$, and $0.015 \mathrm{~mol} \mathrm{~kg} \mathrm{~kg}^{-1}$ ) over the temperature range 5 to $50{ }^{\circ} \mathrm{C}$. The $\mathrm{KD}_{2}$ Cit salt was formed in solution by exchange with $\mathrm{D}_{2} \mathrm{O}$ when $\mathrm{KH}_{2} \mathrm{Cit}$ was dissolved in heavy water.

The measured emf (E) of this cell, together with the standard emf $\left(E^{\circ}\right)$, was used to calculate the acldity function $\mathrm{p}\left(\mathrm{a}_{\mathrm{D}} \gamma_{\mathrm{Cl}}\right)$. The limiting value of the latter $\mathrm{p}\left(\mathrm{a}_{\mathrm{D}} \gamma_{\mathrm{Cl}}\right)^{\circ}$ at zero concentration of added chloride was obtained by least-squares extrapolation.

Conventional pap values were computed by the equation

$$
p a_{D}=p\left(a_{D} \gamma_{C I}\right)^{\circ}+\log \gamma_{C I^{-}}
$$

where the single ionic activity coefficient for the chloride ion was defined by the Bates-Guggenheim convention [13] in 
the form

$$
-\log \gamma_{\mathrm{CI}^{-}}=\frac{\mathrm{AI^{1/2 }}}{1+4.565 \mathrm{BI} I^{1 / 2}}
$$

In equation 3, $A$ and $B$ are the Debye-Hthekel constants adjusted to consistency with the dielectric constant and density of heavy water. The lonic strength I was estimated from the three ionization constants of citric acid [14,15] corrected for isotope effects. The $\mathrm{pa}_{\mathrm{D}}$ values obtained by this method were identified with $\mathrm{pD}(\mathrm{S})$ values for these reference buffer solutions; they are listed in table 5 .

Table 5. Standard reference values of pa for $0.05 \mathrm{~m}$ $\mathrm{KD}_{2}$ citrate in deuterium oxide.
$t,{ }^{\circ} \mathrm{C}$
$\mathrm{pa}_{\mathrm{D}}$
$t,{ }^{\circ} \mathrm{C}$
pa

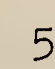

10

15

20

25
4.378

4.352

4.329

4.310

4.293
30

35

40

45

50
4.279

4.268

4.260

4.254

4.250

\section{b. Carbonate Buffer}

The second solution proposed as a new primary reference standard is a mixture of two components, sodium bicarbonate and sodium carbonate, each $0.025 \mathrm{~m}$. This buffer mixture has a $\mathrm{pD}$ value of 10.74 at $25{ }^{\circ} \mathrm{C}$, thus permitting the behavior of the glass electrode to be checked at relatively high alkalinities. 
The sodium bicarbonate and the anhydrous sodium carbonate were commercial samples. The first compound was used without any further treatment. It assayed 99.98 percent (standard deviation 0.03 ) when neutralized with excess standard hydrochloric acid and back-titrated with standard sodium hydroxide solution after boiling to expel the carbon dioxide formed. Anhydrous sodlum carbonate was heated at $275{ }^{\circ} \mathrm{C}$ under an atmosphere of carbon dioxide. It assayed 100.03 percent (standard deviation 0.03 ) when titrated by the same procedure. Coulometric titrations gave an assay of 99.949 percent (standard deviation 0.004) and 99.965 percent (standard deviation 0.02 ), respectively, for the two salts. The coulometric titrations were performed by C. E. Champion of the Microchemical Analysis Section.

The standard values of $\mathrm{pa}_{\mathrm{D}}$ were determined by the method outlined in the previous section. The emf of the following cell was measured:

Pt: $D_{2}(\mathrm{~g}), \mathrm{NaDCO}_{3}(0.025 \mathrm{~m}), \mathrm{Na}_{2} \mathrm{CO}_{3}(0.025 \mathrm{~m}), \mathrm{NaCl}\left(\mathrm{m}_{3}\right), \mathrm{AgCl} ; \mathrm{Ag}$

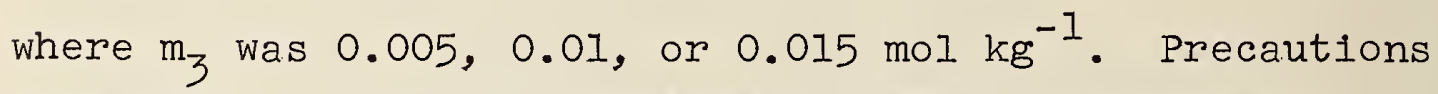
were taken to avoid contamination with carbon dioxide by preparing the cell solutions under an atmosphere of nitrogen. The pa values obtained are listed in table 6 . Equations for the variation of $\mathrm{pa}_{\mathrm{D}}$ with temperature were found with the aid of the CEIR computer, using Dartmouth BASIC Ianguage, and checked by OMNITAB. The smoothed curves of $\mathrm{pa}_{\mathrm{D}} \mathrm{VS}$. temperature are shown in figure 5 . 
Table 6. Standard reference values of pa for the solution 0.025 molal with respect to both $\mathrm{NaDCO}_{3}$ and $\mathrm{Na}_{2} \mathrm{CO}_{3}$ in deuterium oxide.

\begin{tabular}{rccc}
$\mathrm{t},{ }^{\circ} \mathrm{C}$ & $\mathrm{pa}_{\mathrm{D}}$ & $\mathrm{t},{ }^{\circ} \mathrm{C}$ & ${ }^{\mathrm{pa}} \mathrm{D}$ \\
\hline 5 & 10.998 & 30 & 10.685 \\
10 & 10.923 & 35 & 10.638 \\
15 & 10.855 & 40 & 10.597 \\
20 & 10.793 & 45 & 10.559 \\
25 & 10.736 & 50 & 10.527
\end{tabular}

c. Internal Consistency of the pD Scale

The internal consistency of the pD scale fixed by these three buffer solutions was examined by the intercomparison of standards in cells of the types

Pt; $D_{2}(g)$, Standard soln. (S)! KCl (satd.), calomel reference electrode

and

$\mathrm{Pt}_{3} \mathrm{D}_{2}$, Unknown soln. (X) $\mid \mathrm{KCl}$ (satd.), calomel reference electrode

where the vertical line represents a liquid function. The operational pD of the unknown solution is given by the following equation

$$
\mathrm{pD}(\mathrm{X})=\mathrm{pD}(\mathrm{S})+\frac{\mathrm{E}_{\mathrm{X}}-\mathrm{E}_{\mathrm{S}}}{(\mathrm{RT} \ln 10) / \mathrm{F}}
$$

where $\mathrm{pD}(\mathrm{S})$ is the assigned value of the standard reference 
solution and $E_{X}$ and $E_{S}$ are the emf values for the cells containing unknown and standard solutions, respectively. If the reference electrode potential and the liquid-junction potential remain constant when the unknown solution is substituted for the standard solution, $\mathrm{pD}(\mathrm{X})$ will fall on the standard scale of $\mathrm{pa}_{\mathrm{D}}$ on which $\mathrm{pD}(\mathrm{S})$ is based.
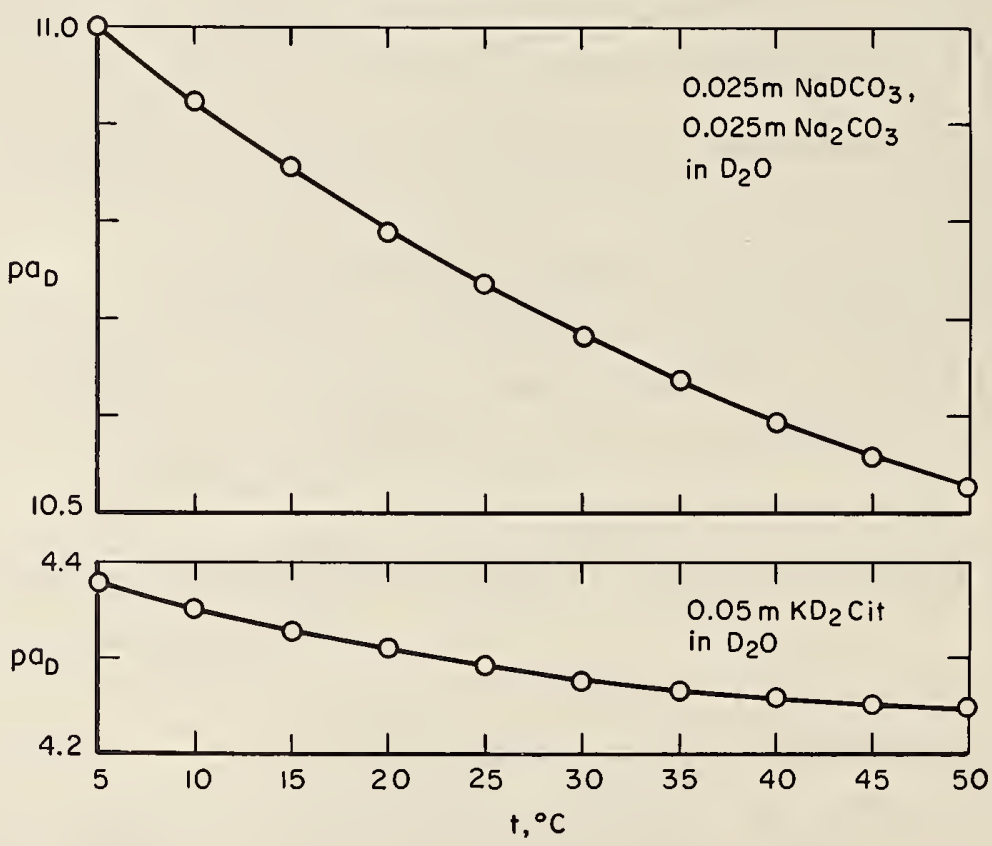

Figure 5. Values of $\mathrm{pD}(\mathrm{S})$ for two primary standards in deuterium oxide as a function of temperature. 
The $0.025 \mathrm{~m}$ phosphate buffer solution was selected as the standard solution $(S)$ and the citrate and carbonate buffer solutions (unknown soln., $\mathrm{X}$ ) were compared with it. The cell vessel used for the comparison permitted two capillary liquid junctions to be formed [9]. The experiment was carrled out with two types of reference electrode, one a calomel electrode prepared in heavy water and the other a calomel electrode in ordinary water. The results are given in table 7 . They indicate that it makes little difference whether the reference electrode and salt bridge are prepared in ordinary water or in heavy water; the residual liquid-junction potential is the same, within experimental error, as long as both the standard and unknown solutions are made up in heavy water.

Table 7. Intercomparison of reference buffers in deuterium oxide at $25{ }^{\circ} \mathrm{C}$ measured against the phosphate buffer standard $[\mathrm{pD}(\mathrm{S})=7.429]$.

\begin{tabular}{|c|c|c|c|c|c|}
\hline \multirow[b]{2}{*}{$\begin{array}{l}\text { Reference } \\
\text { Buffer }\end{array}$} & \multirow[b]{2}{*}{$p a_{D}$} & \multicolumn{2}{|c|}{$\mathrm{D}_{2} \mathrm{O}$ ca.lome 1} & \multicolumn{2}{|c|}{$\mathrm{H}_{2} \mathrm{O}$ calomel } \\
\hline & & $\begin{array}{l}\mathrm{pD} \\
(\mathrm{obs} .)\end{array}$ & $\mathrm{pD}-\mathrm{pa}$ & $\begin{array}{c}\mathrm{pD} \\
(\mathrm{obs} .)\end{array}$ & $p D-p a_{D}$ \\
\hline Citrate & 4.293 & 4.304 & +0.011 & 4.305 & +0.012 \\
\hline Carbonate & 10.736 & 10.729 & -0.007 & 10.728 & -0.008 \\
\hline
\end{tabular}


3. Certification of Standard Reference Materials

Four new lots of buffer materials to be issued as pD standards have been acquired. The new Standard Reference Materials have been given the following numbers:

$\begin{array}{ll}\text { Potassium dihydrogen phosphate } & \text { SRM No. } 2186 I \\ \text { Disodium hydrogen phosphate } & 2186 I I \\ \text { Sodium bicarbonate } & 2191 \\ \text { Sodium carbonate } & 2193\end{array}$

Standard reference values of $\mathrm{pD}(\mathrm{S})$ were assigned to buffer solutions prepared from these naterials. The method of assignment was an abbreviated version of the procedure for determining pa values described in the previous sections of this report.

The phosphate buffer materials were each supplied in a single container. An estimate of the homogeneity of the contents of each container was first made. Two individual samples were removed from each lot and tested for adherence to the purchase specifications. No difference was found. The following tests were performed: hydrogen ion test, ignition test, and acid-base titration.

Only a single lot of each of the carbonate salts was acquired for issuance as Standard Reference Materials for use in both heavy water and ordinary water. The tests for homogeneity and for assay on these materials are described in section 2.C of this report. The emf measurements with the phosphate and carbonate buffer solutions in heavy water were performed in the usual manner, already described. One added complication, however, was encountered.

After the values of the acidity function $\mathrm{p}\left(\mathrm{a}_{\mathrm{D}} \gamma_{\mathrm{Cl}}\right)$ had been obtained for each buffer solution, it was noted that they were consistently higher by 0.003 to $0.006 \mathrm{pD}$ unit over the entire range than those obtained earlier in the 
Section. This was thought to be caused by a difference In the heavy water used. On examination, the new lot of heavy water was found to be slightly radioactive (about $\left.0.4 \mu \mathrm{Ci} / \mathrm{cm}^{3}\right)$. However, no activity beyond that of the background was observed when two samples of heavy water used earlier were examined. The radioactivity measurements were performed by Dr. H. I. Frush. The amount of tritium oxide indicated is very small. It is estimated to be about $10^{-8} \mathrm{~mol} \mathrm{~kg}^{-1}$.

Unfortunately, no non-radioactive heavy water was Immediately available. Hence, the emf measurements were repeated, for one selected ratio of buffer to sodium chloride, in heavy water that had a relatively low activity (about $0.14 \mu \mathrm{Ci} / \mathrm{cm}^{3}$ ). The values of the acidity function $\mathrm{p}\left(\mathrm{a}_{\mathrm{D}} \gamma_{\mathrm{Cl}}\right)$ found were identical with those previously obtained with inactive heavy water, within experimental error limits. A set of $\mathrm{pD}(\mathrm{S})$ values was thus calculated for each buffer mixture, combining the results reported by Gary et a1. [11] (phosphate) or those given in Section 2.D.2 of this report (carbonate) with the data obtained from measurements in the mildly radioactive $D_{2} O\left(0.14 \mu \mathrm{Ci} / \mathrm{cm}^{3}\right)$. On the average, the certified values for the new standard Reference Materials differ but slightly from those found in the extensive work done earlier by Gary et al. and those given in table 6 . The average difference is less than 0.001 unit.

(M. Paabo) 
E. Measurement of Acidity in Sea Water

This work has as its objective the development of $\mathrm{pH}$ standards for media approximating sea water in composition. These reference standards would be useful in adjusting pH equipment used for accurate determinations of hydrogen ion concentration or activity in oceanographic studies. They would be made available through the standard Reference Materials program.

During the reporting year, electrochemical studies of the behavior of hydrochloric acid in simulated sea water (SSW) were continued at Clarkson College of Technology under a cooperative arrangement with Professor Donald Rosenthal. The medium is an aqueous mixture of the chlorides of sodium, magnesium, calcium, strontium, and potassium. It matches closely the ionic strength and composition of natural sea water. When completed, the data will yield the standard potential of the cell: $\mathrm{Pt} ; \mathrm{H}_{2}, \mathrm{HCl}$ in SSW, $\mathrm{AgCl}$; Ag over the temperature range 5 to $35^{\circ} \mathrm{C}$.

A computer program facilitating the correction of the observed emf to the standard hydrogen pressure, as well as the calculation of acidity functions $p\left(a_{\mathrm{H}} \gamma_{\mathrm{Cl}}\right)$ from the corrected emf, has been written. New cells and a new hydrogen supply line were constructed. Difficulties were experienced in obtaining reproducible data at $45{ }^{\circ} \mathrm{C}$; since this temperature is of limited oceanographic interest, it was decided to place an upper limit of $35{ }^{\circ} \mathrm{C}$ on the temperature range studied. The planned experiments were continued but are not yet completed.

$$
\text { (J. T. Clark, Jr.) }
$$


A. Ion-Solvent Interactions

In its research interests, the section is intimately concerned with the relationship between the behavior of electrolytes in solution and the properties of the solvent medium. It is well known that relatively small changes in the composition of the solvent often have a very large effect on the ionic processes taking place. Nevertheless, there is very little understanding of the mechanisms of these profound effects and of the complex interactions which bring them about.

The interactions of ions which lead to the formation of ion pairs and higher aggregates can be investigated by a variety of physicochemical techniques, including conductance, potentiometry, and spectrophotometry. The key to an understanding of solvent effects, however, appears to lie in the interactions between ions and solvent molecules, and these processes are much less accessible to detailed study. In a mixed solvent, it may be particularly difficult to identify the factors responsible for acid-base behavior. In these situations, the solvent not only furnishes the medium for the reaction of an acid and a base: in adition, the two types of solvent molecules may interact differently with the reactants and products of the primary acid-base process.

In a general way, ion-solvent processes provide a unifying theme for a large part of the research activity of the section. Solvent effects on ionic equilibria and medium effects for individual chemical species are being determined. The results may be expected to shed some light on the nature of the parameters governing the interaction of solute species with solvent molecules. This subject is also being attacked from the point of view of 
transport processes such as conductance and diffusion. Progress in this area, we believe, is an essential prerequisite to advancements in the electrochemistry of nonaqueous solutions. Furthermore, numerical scales of ionic transfer free energies based on either experiment or theory will provide the basis not only for a unified scale of single electrode potentials but for a single acidity scale for all solvents in which the proton is the acidic element.

(R. G. Bates)

B. Water Structure and Medium Effects in Mixed Aqueous Solvents

In an important paper published in 1948, Braude and Stern [16] reported the measurement of Hammett acidity functions for hydrogen chloride in aqueous solvent mixtures and in mixed solvents containing no water. The differences between the results in these two groups of solvents, one containing water and the other completely nonaqueous, were striking. When the solvent contained water, the acidity of the hydrochloric acid solutions appeared to decrease as the mixture was enriched with the organic constituent (ethanol, acetone, or dioxane) to a minimum value in the vicinity of a composition of 50 mole percent. Above this composition, it increased again, and, when the proportion of water in the solvent mixture approached zero, the apparent acidity might exceed that of the pure aqueous solution. On the contrary, the addition of dioxane or acetone to an ethanolic solution of hydrogen chloride was almost without effect on the apparent acidity up to a composition of 50 mole percent. At higher acetone concentrations, solutions of hydrochloric acid displayed a gradually increasing acidity. When dioxane was added above the 50 mole percent level, the acidity gradually decreased. The rate of decrease accelerated as the last of the ethanol was removed. 
Evidently the presence of water in binary mixed solvents has a rather profound and anomalous effect on acid-base behavior in these mixtures. Braude and Stern attributed the contrasting behavior to a quasi-crystalline tetrahedral structure which conditions the unique properties of water [see 17]. According to this view, the proton affinity of the individual water molecules is partly satisfied by hydrogen bonding with nelghboring molecules. On the addition of an organic solvent to the purely aqueous medium, this structure is gradually broken down, and hydrogen bonding between neighboring water molecules is partly replaced by much weaker bonding with organic solvent molecules. The result is that the effective proton affinity of the water molecules increases.

As the proportion of organic solvent is raised, the aqueous solvation shell is gradually dispersed and the aqueous solvates (protons associated with more than one molecule of water) are replaced by hydronium ions $\mathrm{H}_{3} \mathrm{O}^{+}$. It was suggested that this condition is reached at the minimum in the acidity curve. When still more organic solvent is added, the hydronium ions are gradually replaced by organic oxonium ions of the type $\mathrm{EtOH}_{2}{ }^{+}$. The behavior of water in mixed solvents is thus conditioned by the unusual structure of water and by its exceptionally high proton affinity.

For an improved understanding of the structural properties of alcohol-water mixtures we are indebted to a recent review by Franks and Ives [18]. These authors have shown that the thermodynamic excess functions, partial molar volumes, densities, sound absorption, spectroscopic properties, and dielectric constants of alcohol-water mixtures are qualitatively consistent with the views given above. One conclusion stands out, however. When alcohols 
and certain other hydrogen-bonding organic liquids are added to pure water, an initial increase in structure may occur, due to the enhanced possibilities for hydrogen bonding. This effect persists only to a composition of a few weight percent of the organic constituent, after which breakdown of structure ensues.

One of the remarkable consequences of this change in solvent structure when water is present is the existence of a minimum in the pK value for a positively charged acid (such as ammonium ion and substituted anilinium ions, for example) as the aqueous solvent is enriched with an organic constituent. When the solvent mixture contains no water, this minimum is absent, as shown in figure 6 . The pK values

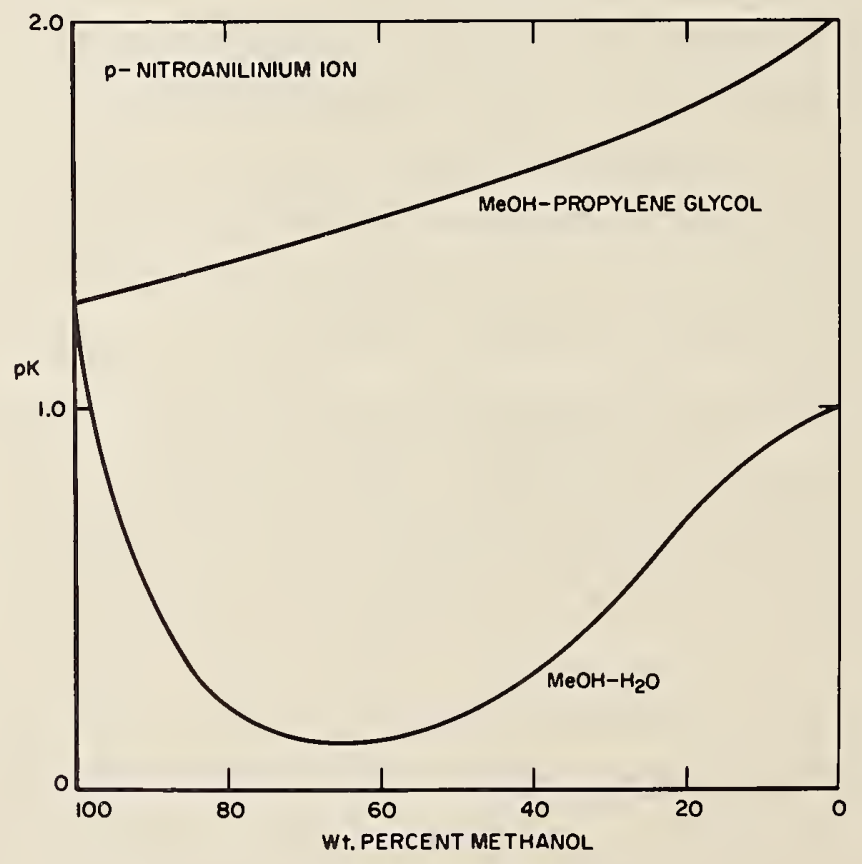

Figure 6. Solvent effect on the dissociation of p-nitroanlinium ion in methanol-water solvents compared with that in methanolpropylene glycol solvents. 
plotted in the upper portion of the figure were obtained recently by Kundu, De, and Das [19].

If the initial effect of adding the organic component to an aqueous solution is to increase structure, it is possible that the $\mathrm{pK}$ values of an acid of this charge type may actually increase initially before falling off. It is uncommon to measure $\mathrm{pK}$ between 0 and $10 \mathrm{wt}$. percent of the organic constituent, but a careful examination of the best pK data reveals a flattening of the curve in this region, that is, a delayed drop in pK [20-22].

According to the evidence presented by Franks and Ives [18], tert-butanol is particularly effective in bringing about increased water structure. It seemed of interest, therefore, to examine the change in $\mathrm{pK}$ for a cation acid in water-tert-butanol mixtures containing between 0 and 10 wt. percent of the organic component. The dissociation constant of m-nitroanilinium ion can be obtained readily by spectrophotometric measurements in solutions of a strong acid; consequently, this system was chosen for study. Within the uncertainty of the measurements (about 0.006 in $\mathrm{pK}$ ), no increase was found, nor did the addition of tert-butanol in amounts of 3 to 5 percent produce a significant decrease in $\mathrm{pK}$. Although these results are not highly conclusive, they suggest that increases in the structure of an already highly structured water result in only relatively small changes in the proton affinity of the solvent medium.

(M. Alfenaar, R. G. Bates) 
C. Structural Effects in N-Methylpropionamide-Water

\section{Mixtures}

Densities and dielectric constants of mixtures of $\mathrm{N}$-methylpropionamide (NMP) and water were presented in the annual progress report for 1967 [2]. A paper in press discusses these results in relation to the structure of solutions by comparison with the systems consisting of water and each of three other organic liquids: N-methylacetamide (NMA), ethanol, and acetic acid.

In the essentially aqueous range of compositions, an informative parameter is the apparent change in volume of a mole of the organic component on being transferred from the pure organic liquid to a dilute aqeuous solution. This change, $\Delta V$, as shown in figure 7 , is negative for all the

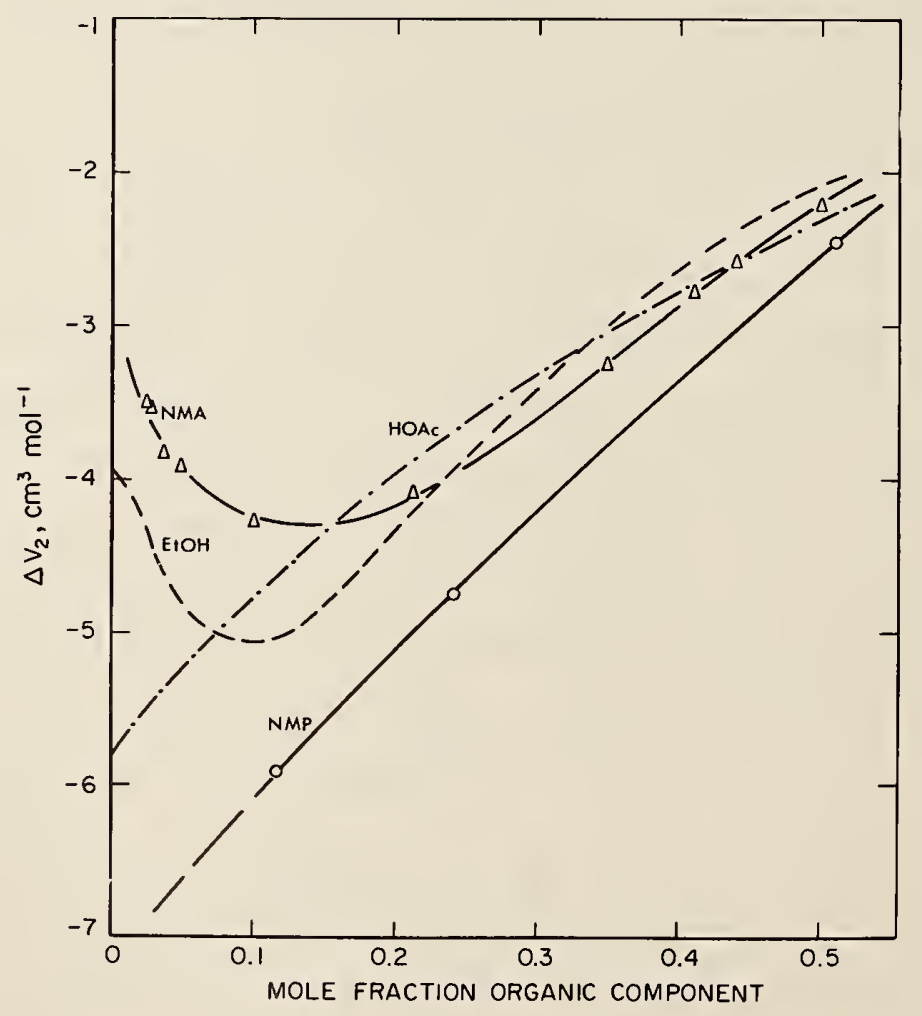

Figure 7. Molar volume of transfer from pure organic Iiquid to aqueous solution at $30^{\circ} \mathrm{C}$. 
systems, corresponding to a contraction in volume for the solutions, but it shows a distinct minimum for ethanol and NMA at 10 to 15 mole percent of the organic solute. The minimum has been interpreted [18] as resulting from competing effects of the polar and non-polar ends of the organic molecule upon the structure of the water. NMP, in contrast to Its homologue NMA, appears more like acetic acid in showing the greatest contraction in the infinitely dilute solution. The measurements were not carried to sufficiently low concentrations of NMP, however, to establish this conclusion reliably.

In the composition range where water is the minor component, a more revealing structural insight is given by the dielectric measurements. A pseudo-Kirkwood correlation parameter, $g$, was calculated on the basis that the square of the effective dipole moment and the high-frequency dielectric constant of the binary mixture can be expressed as linear functions of the mole fractions of the components. As shown in figure 8, the two amides resemble each other quite closely. NMP has the higher $g$ value in the pure liquid, corresponding to greater parallel orientation of the dipoles in chain-wise association [23], but the g value for NMP also decreases more rapidly than that for NMA with the addition of water. The decrease indicates the effect of water in breaking up the amide-amide associations. As has been noted [18], ethanol and water form a mixture in which $\mathrm{g}$ is virtually constant over the whole range of compositions. The acetic acid system is very similar to the ethanol system up to a composition of 50 mole percent acetic acid. With increasing acid content, $g$ decreases, becoming less than unity when the mixture contains more than 90 mole percent of acetic acid. The latter fact reflects the anti-parallel orientation of dipoles in acetic acid dimers. 


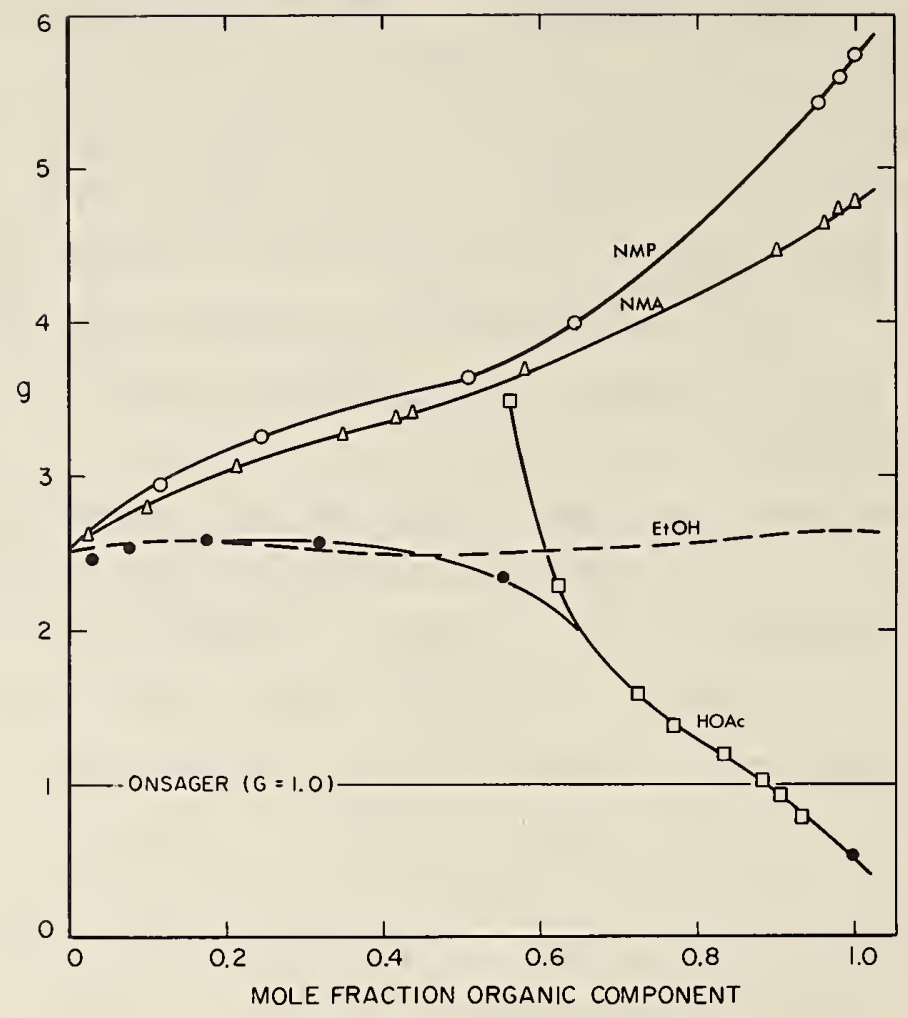

Figure 8. Pseudo-Kirkwood correlation parameters for binary mixtures of water and organic liquids.

(T. B. Hoover)

D. Emf Studies in Methanol-Formamide Mixtures

As pointed out in Section 3.B, there is good reason to regard water to be anomalous in its influence on acid-base behavior. It is therefore instructive to study the solvent effects produced by nonaqueous binary solvent mixtures. To preserve the general simllarity to mixtures containing water, one component should have hydrogen-bonding capabilities; the other might well be aprotic. Methanol is useful 
as the hydrogen-bonding component. Formamide or propylene carbonate can be added to it to provide mixtures covering a considerable range of dielectric constants.

Exploratory emf measurements in formamide and in a mixture of formamide and methanol containing 50 wt. percent of each component were made. Hydrochloric acid was added to each cell solution in a concentration of about 0.03 mol $\mathrm{kg}^{-1}$. The experiments were designed to test the stability of the solutions and of the hydrogen and silversilver chloride electrodes in these solvent systems.

The observed emf of each solution increased steadily with time, and the drift was more rapid for the methanolformamide mixture than for the pure formamide solvent. Over a period of six hours, the emf for the mixed solvent increased from $0.6271 \mathrm{~V}$ to $0.6317 \mathrm{~V}$. The hydrogen flow was continued overnight, and on the following day the emf had risen to $0.6429 \mathrm{~V}$. In the same time intervals, the cell containing pure formamide showed an increase from 0.6592 to $0.6606 \mathrm{~V}$, and further to $0.6616 \mathrm{~V}$ on the next day.

This instability of the mixed solvent is too great to permit solvent effects on the properties of strong electrolytes, and on the $\mathrm{pK}$ of weak electrolytes, to be studied with the accuracy desired. Moreover, formamide is difficult to purify, and its instability demands that it be freshly distilled before use. Hence, further work with this solvent was abandoned in the hope that mixtures of methanol and propylene carbonate would prove more suitable.

(B. R. Staples) 
E. Emf Studies in Methano1-Propylene Carbonate Mixtures

Preliminary emf measurements were made on solutions of hydrochloric acid $(0.02 \mathrm{~m})$ in both pure propylene carbonate and a mixture containing 50 wt. percent of methanol and propylene carbonate. The objective was to ascertain the feasibility of using these solvent systems for potentiometric studies, particularly for the determination of $\mathrm{pK}$ values for comparison with solvent effects found in the methanol-water system.

The uncorrected values of the emf recorded over a period of several days are listed in table 8 . Initial equilibrium was achieved rapidly. It is evident that the methanol-propylene carbonate system is much more stable than the propylene carbonate solution.

Table 8. Emf of the cell: Pt; $\mathrm{H}_{2}, \mathrm{HCl}(0.02 \mathrm{~m})$ in solvent $\mathrm{a}$ or $\mathrm{b}, \mathrm{AgCl} ; \mathrm{Ag}$ at $25^{\circ} \mathrm{C}$ (in volts).

Days after

preparation a

Propylene carbonate 50 wt. percent $\mathrm{MeOH}-$ propylene carbonate

$\begin{array}{lll}1 & 0.02390 & 0.19743 \\ 2 & 0.0167 & 0.19665 \\ 3 & 0.0103 & 0.19563 \\ 6 & 0.011^{*} & 0.19534\end{array}$

* unstable emf

Propylene carbonate has many advantages over formamide for studies of the type we wish to perform. Among them are a greater stability and greater ease of purification (see Section 7.A). Although the emf is not as constant as might 
be desired, it seems feasible to use mixtures of methanol and propylene carbonate in the study of solvent effects on acid-base processes.

Two series of measurements of hydrochloric acid solutions directed toward a determination of the standard emf of the cell in 50 wt. percent methanol-propylene carbonate were carried out over the temperature range 0 to $40{ }^{\circ} \mathrm{C}$. Further information needed for the evaluation of the results includes vapor pressures of the solutions and dielectric constants of the solvents over the temperature range studied.

$$
\text { (B. R. Staples) }
$$

F. Emf Studies in N-Methylpropionamide-Hydrocarbon Mixtures

Electromotive-force studies in $\mathrm{N}$-methylpropionamide were begun by $D$. Rosenthal in the Section and were described in last year's report [2]. This study has been continued with further work at NBS between June and September 1967 and, in cooperation with Professor Rosenthal, at Clarkson College of Technology during the academic year 1967-68. An extension of the measurements of the cell

Pt; $\mathrm{H}_{2}(\mathrm{~g}), \mathrm{HCl}(\mathrm{m})$ in nonaqueous solvent, $\mathrm{AgCl} ; \mathrm{Ag}$ with N-methylpropionamide (NMP) as solvent was first made, to complete the molality range 0.005 to $0.1 \mathrm{~mol} \mathrm{~kg}^{-1}$ at temperature intervals of $10{ }^{\circ} \mathrm{C}$ from 5 to $55^{\circ} \mathrm{C}$. The experimental data have been obtained, and an analysis of the results is under way. The data will yield the standard emf of the cell, the mean molal activity coefficient of hydrochloric acid at various round molalities, as well as the relative partial molal enthalpy and heat capacity for HCl in this nonaqueous medium. Computer programs have been written to facilitate the calculations. 
In new work undertaken during the year, an attempt is being made to clarify the nature of solvent effects through the study of "isodielectric" solvents. N-methylpropionamide has a very high dielectric constant (175.6 at $25^{\circ} \mathrm{C}$ ). Consequently it is possible, by adding inert nonpolar organic liquids to NMP, to form mixtures having the same dielectric constant as water at $25{ }^{\circ} \mathrm{C}(78.3)$. As a first approximation, ions dissolved in such isodielectric solvents should be subject to identical electrostatic effects in each medium; hence, observed solvent effects on acid-base processes in these solvents might reveal other ion-solvent interactions that are sometimes obscured by the large influence of unequal electrostatic forces.

Two nonaqueous mixed solvents with the same dielectric constant as water are being studied. These are NMP-cyclohexane and NMP-decalin (decahydronaphthalene). In the cyclohexane system, emf measurements have been made from 5 to $35^{\circ} \mathrm{C}$ on solutions of hydrochloric acid with molalities from 0.005 to $0.1 \mathrm{~mol} \mathrm{~kg}^{-1}$. Independent determinations of the appreciable solvent vapor pressure were necessary in order to interpret the results.

In the decalin system, emf measurements have been made from 5 to $55{ }^{\circ} \mathrm{C}$ on solutions of hydrochloric acid with molalities from 0.005 to $0.05 \mathrm{~mol} \mathrm{~kg}^{-1}$. The vapor pressure of this solvent mixture is negligible, and no corrections were necessary to obtain the effective partial pressure of hydrogen. Experimental measurements have been completed, and the analysis of the results is in progress.

(E.S.Etz) 
A. General Principles

Several different ion-selective electrodes have been developed in recent years and have found many applications in the determination of ion concertrations and activities. With the widespread use of these new tools, problems concerning uniform standardization procedures have arisen.

At the request of several persons and organizations concerned with construction, development, and application of these electrodes, a program has been started in the Section to develop standardization methods and standard reference materials for use with ion-selective electrodes. In response to this demand a standardization procedure analogous to that generally accepted for the measurement of hydrogen ion activities (pH) is being developed. Thus far, the usefulness of this method has been demonstrated for chloride-selective and sodium-selective electrodes.

In the approach chosen, an operational definition of the negative logarithm of the activity of an ionic species A (designated $\mathrm{pA}$ ) is formulated as follows:

$$
\mathrm{pA}(\mathrm{X})=\mathrm{pA}(\mathrm{S})+\frac{\mathrm{E}_{\mathrm{X}}-\mathrm{E}_{\mathrm{S}}}{(\mathrm{nRT} \ln 10) / \mathrm{F}}
$$

in which $E_{X}$ and $E_{S}$ are respectively the emf values for the cells $X$ and $S$ and $n$ is the number of charges borne by the ion A:

Ion-selective Soln. $X$ electrode,
Salt bridge,
Reference

electrode

and

Ion-selective electrode,
Soln. S (pA known)
Salt bridge,
Reference electrode 
Three considerations are important for the interpretation of $\mathrm{pA}(\mathrm{X})$ in terms of the ionic activity in solution $\mathrm{X}$.

1. The activity assigned to the ionic species in the standard solution $(S)$.

2. The liquid-junction potentials between the salt bridge and the solutions in which the measurements are made.

3. The response of the ion-selective electrode with respect to ionic activity, ionic compositions of the solutions, time variations, and the like.

1. Definition of Activity Coefficients

As is well known, the activity of single ions is a quantity that is not accessible to direct measurement. It can only be estimated, and for this reason any pA value assigned to standard solutions is devoid of exact fundamental meaning. In the establishment of a standard $\mathrm{pH}$ scale, the following convention for the activity coefficient of chloride ion was adopted [13]:

$$
\log \gamma_{\mathrm{Cl}^{-}}=\frac{-\mathrm{A} I^{1 / 2}}{1+1.5 I^{1 / 2}}
$$

for use at ionic strengths no greater than 0.1. In this equation, $I$ is the lonic strength (molal scale) and $A$ is the Debye-Hthckel slope constant, having a different value at each temperature and dielectric constant of the solvent. In accord with this convention, the $\mathrm{pCl}$ of a standard chloride solution can be defined by

$$
\begin{aligned}
\mathrm{pCl}=-\log \mathrm{a}_{\mathrm{Cl}^{-}}=-\log \left(\mathrm{m}_{\mathrm{CI}^{-}} \cdot \gamma_{\mathrm{CI}^{-}}\right) & =-\log \mathrm{m}_{\mathrm{Cl}^{-}} \\
+ & \frac{\mathrm{AI^{1 }}}{1+1.5 I^{1 / 2}}
\end{aligned}
$$


For the standardization of ion-selective electrodes, it is proposed that equation 6 be applied at all temperatures and at a.1 ionic strengths.

It should be emphasized that a conventional definition of the activity coefficient is needed for only one ionic species. With its adoption, the activity coefficients of all other ions, in theory, become fixed by their interrelationships to the standard ion through mean activity coefficients or other measurable combinations of ionic activity coefficients. Thus, this convention for $\gamma_{\mathrm{Cl}^{-}}$ makes it possible to estimate the activity coefficients of cations from the mean activity coefficients of their chlorides. The proposed definition has the advantage that it interrelates the activity scales of all lons and incorporates the already existing and generally accepted $\mathrm{pH}$ scale into a single conventional array. This ápproach was chosen as the most suitable one after several different means for the estimation of activity coefficients were examined and compared.

\section{Iiquid-Junction Potentia.is}

Iike the single-ion activity, the single-electrode potential and the liquid-junction potential are also inaccessible to direct measurement. Once the activity scale is defined, however, the liquid-junction potential likewise becomes fixed. The magnitude of this diffusion potential (Iiquid-junction potential) can be obtained from measurements of cells of the type

Ag;AgCl, Soln. of known pCl l Salt bridge, Reference electrode

In which the location of the liquid junction is indicated by the vertical line. The emf, E, of this cell, for example, 
is given by

$$
E=E_{r e f}^{\circ}-E_{A g C l}^{\circ}+\frac{R T}{F} \ln a_{C 1}+E_{j}
$$

where $E^{\circ}$ is the standard electrode potential and $E_{j}$ is the liquid-junction potential.

By varying the composition and ionic strength of the solution, the effect of these changes on the liquid-junction potential can be found. Only when $E_{f}$ remains unchanged by the replacement of the standard solution $S$ by the "unknown" solution $X$ does the experimental $\mathrm{pA}(\mathrm{X})$ obtained from equation 5 correspond closely with - log $a_{A}$ in solution $X$. This problem is identical with that which complicates the useful interpretation of experimental pH numbers [24].

\section{Electrode Response}

In general, ion-selective electrodes belong to the class of membrane electrodes. The electrode response is primarily determined by the ratio of the activities of the selected ionic species on the two sides of the membrane and by the relative mobilities of all ions through the membrane. For the perfect electrode, the transference number of the selected ion (A) will be 1 . In this ideal situation, the potential of the electrode $\left(\mathrm{E}_{e l}\right)$ obeys the Nernst equation

$$
E_{e l}= \pm \frac{R T}{n F} \ln a_{A}
$$

No membrane is completely selective, however, and one of the objectives of this study is to ascertain the magnitude of the effect on the electrode response of "inert" salts or ions present in the solution of the ionic species to be determined. The desired information can be obtained by comparing the response of the ion-selective electrode 
with that of a "norm" electrode in suitable electrolyte solutions. For instance, the silver-silver chloride electrode is a useful "norm" for the study of chloride ion response. Ions known to react chemically with the electrode materials were excluded.

The time response is another important characteristic of the electrode. In this connection, it is important to know not only the length of time required for a constant potential to be reached but also the reproducibility of this equilibrium or steady-state value.

(M. Alfenaar)

B. Measurement of Chloride Ion Activity

The behavior of two types of chloride-selective electrodes was examined. One electrode was of the "solid state" design and the other utilized a membrane of the liquid ionexchanger type. A plot of some of the results obtained with one electrode of the former type in sodium chloride solutions is shown in figure 9. Similar results for equimolal mixtures of sodium chloride and potassium nitrate are shown in figure 10.

The experimental values of $-\log \gamma_{\mathrm{C} 1^{-}}$at different ionic strengths and in different electrolyte solutions were obtained with electrodes standardized in a sodium chloride solution of molality $0.01 \mathrm{~mol} \mathrm{~kg}^{-1}$, for which $\mathrm{pCl}$ was taken to be 2.044 at $25{ }^{\circ} \mathrm{C}$ in accordance with equation 7 . The curves in figure 9 represent three different "theoretical" values of $-\log \gamma_{\mathrm{CI}^{-}}$. Curve $I$ and the curve in figure 10 were derived from equation 6 , while the other two curves show the result obtained when $\gamma_{C I^{-}}$is set equal to the mean activity coefficient of sodium chloride (curve 2) and the mean activity coefficient of potassium chloride (curve 3) in their pure aqueous solutions. The latter convention is 
that suggested by Garrels [25]. Studies such as these are useful in selecting procedures for the standardization of these electrodes and in making predictions concerning the precision of experimental measurements of ionic activities.

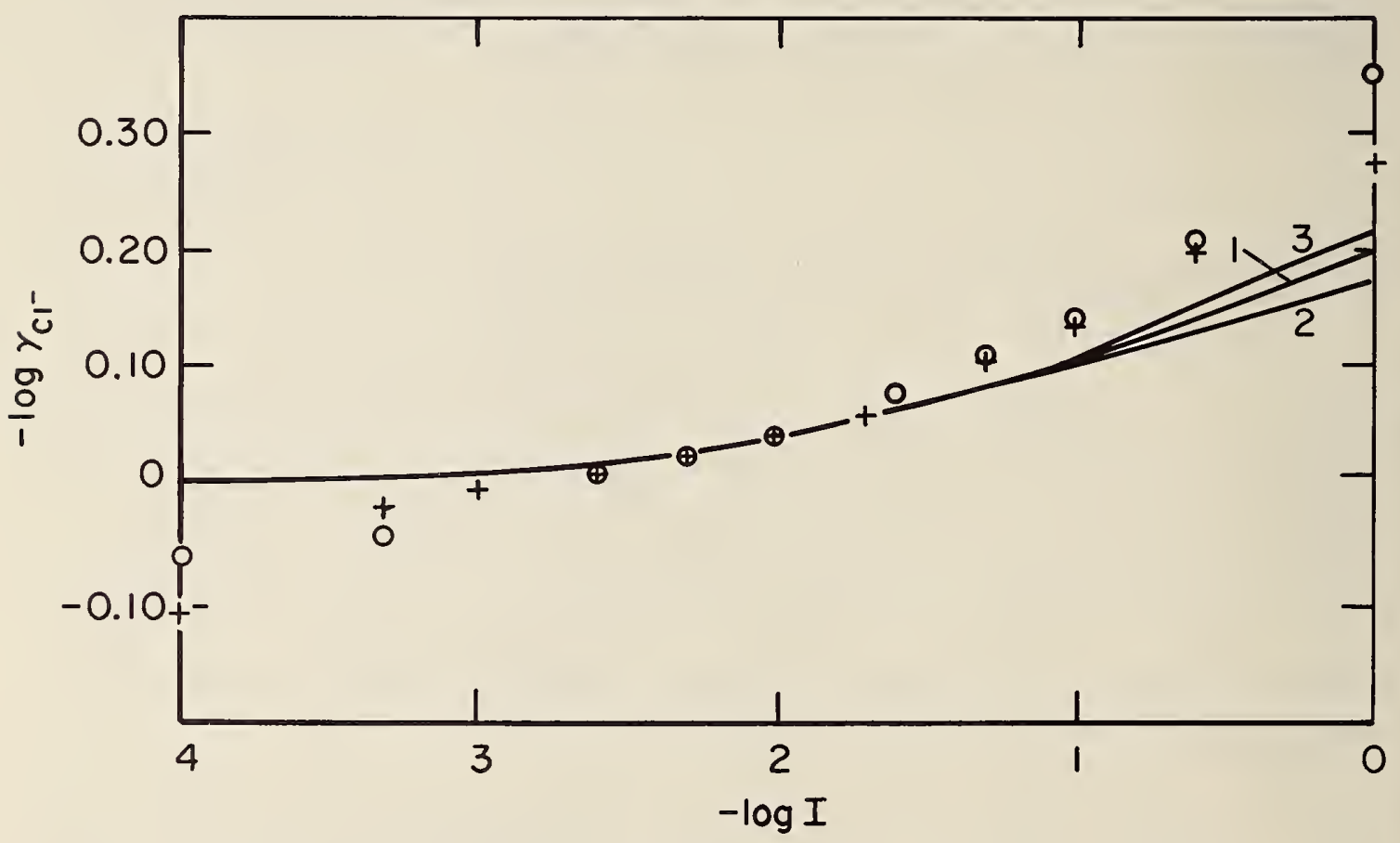

Figure 9. Response of a chloride ion-selective electrode in solutions of sodium chloride at $25^{\circ} \mathrm{C}$. Circles, ion-selective electrode; crosses, Ag; AgCl electrode. Curves calculated from theory, see text. 


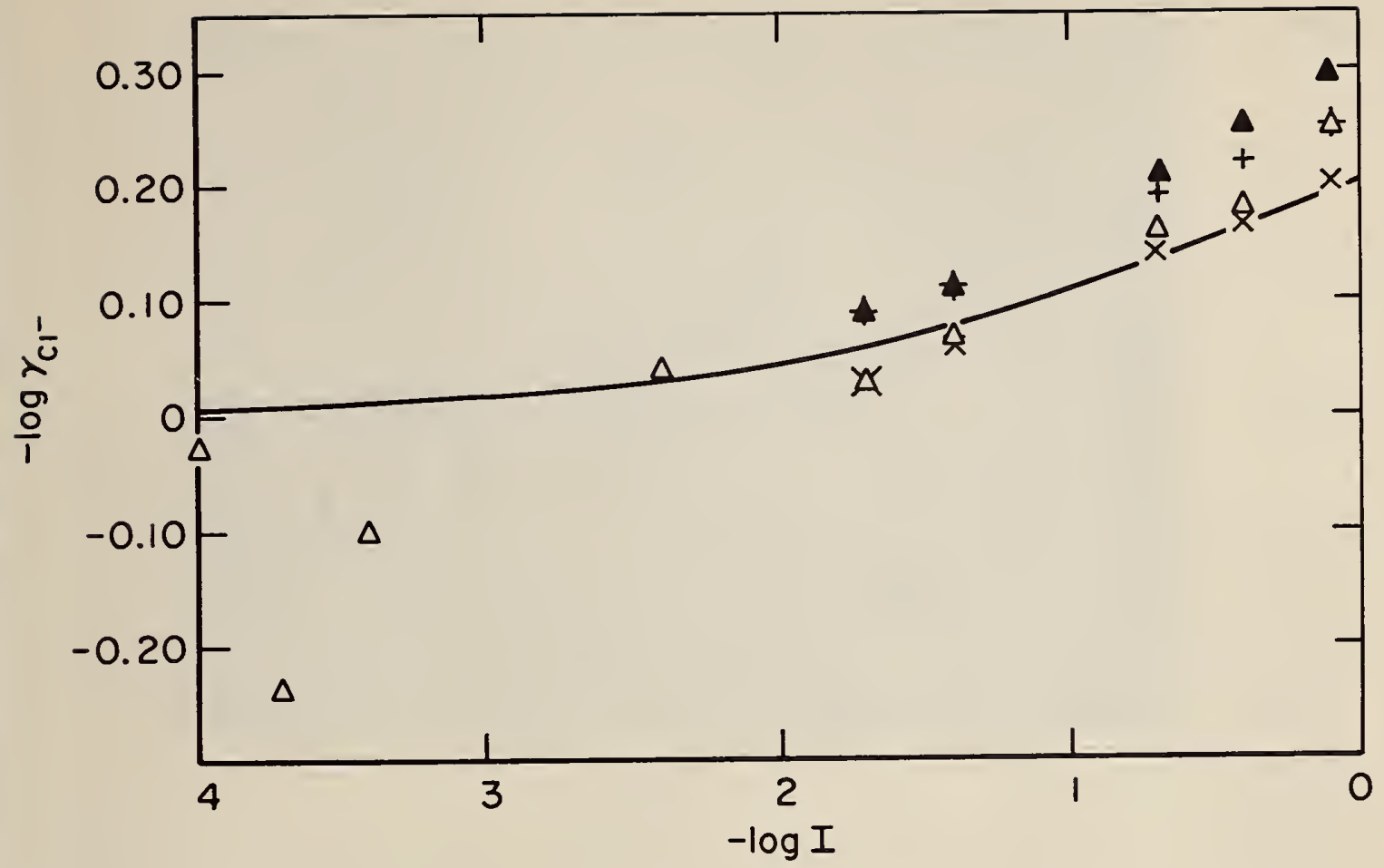

Figure 10. Response of a chloride ion-selective electrode in equimolal mixtures of sodium chloride and potassium nitrate at $25{ }^{\circ} \mathrm{C}$.

$\mathrm{X}$, triangles: ion-selective electrode $\underline{\mathrm{VS}}$. two different reference electrodes.

+ filled triangles: Ag; AgCl electrode vs. two different reference electrodes

Curve from theory, see text.

(M. Alfenar)

C. Measurement of Sodium Ion Activity

In table 9, values for - log $\gamma_{\mathrm{Na}^{+}}$in aqueous solutions of different sodium salts, measured with a commercial sodium-responsive glass electrode fabricated from NAS 11-18 glass and standardized in $0.01 \mathrm{~m}$ sodium chloride ( $\mathrm{pNa}=2.044$ at $25^{\circ} \mathrm{C}$ ), are listed. Two different reference electrodes gave results agreeing, on the average, to 0.01 unit in pNa. The equipment used for the studies of ionic activity described above is shown in figure 11. 
Table 9. Experimental determination of -log $\gamma_{\mathrm{Na}^{+}}$in solutions of sodium salts at different ionic strengths from measurements with a sodiumselective NAS 11-18 glass electrode at $25^{\circ} \mathrm{C}$.

"Observed" - Iog $\gamma_{\mathrm{Na}}+$ in solutions of -

I $\quad \mathrm{NaCl} \quad \mathrm{NaNO}_{3} \quad \mathrm{Na}_{2} \mathrm{SO}_{4} \quad \mathrm{NaCl}^{-\mathrm{KNO}_{3}} \begin{array}{r}\text { Calculated } \\ -\log \gamma_{\mathrm{Na}}+\end{array}$

\begin{tabular}{lccccl}
0.0001 & -0.25 & - & -0.23 & - & 0.005 \\
0.00025 & -0.04 & - & -0.11 & - & 0.01 \\
0.0005 & -0.02 & - & - & - & 0.01 \\
0.001 & 0.02 & - & 0.01 & - & 0.02 \\
0.0025 & 0.03 & - & 0.02 & - & 0.02 \\
0.005 & 0.03 & - & - & - & 0.03 \\
$0.01 *$ & $0.041^{*}$ & 0.04 & 0.04 & - & $0.044 *$ \\
0.02 & - & - & - & 0.03 & 0.06 \\
0.025 & 0.06 & - & 0.06 & - & 0.07 \\
0.04 & - & - & - & 0.06 & 0.08 \\
0.05 & 0.08 & - & - & - & 0.09 \\
0.1 & 0.08 & 0.08 & 0.11 & - & 0.10 \\
0.2 & - & - & - & 0.12 & 0.11 \\
0.25 & 0.10 & - & 0.10 & - & 0.12 \\
0.4 & - & - & - & 0.13 & 0.14 \\
0.8 & - & - & - & 0.15 & 0.15 \\
1.0 & 0.08 & 0.09 & 0.23 & - & 0.16 \\
\hline
\end{tabular}

* Standard solution 


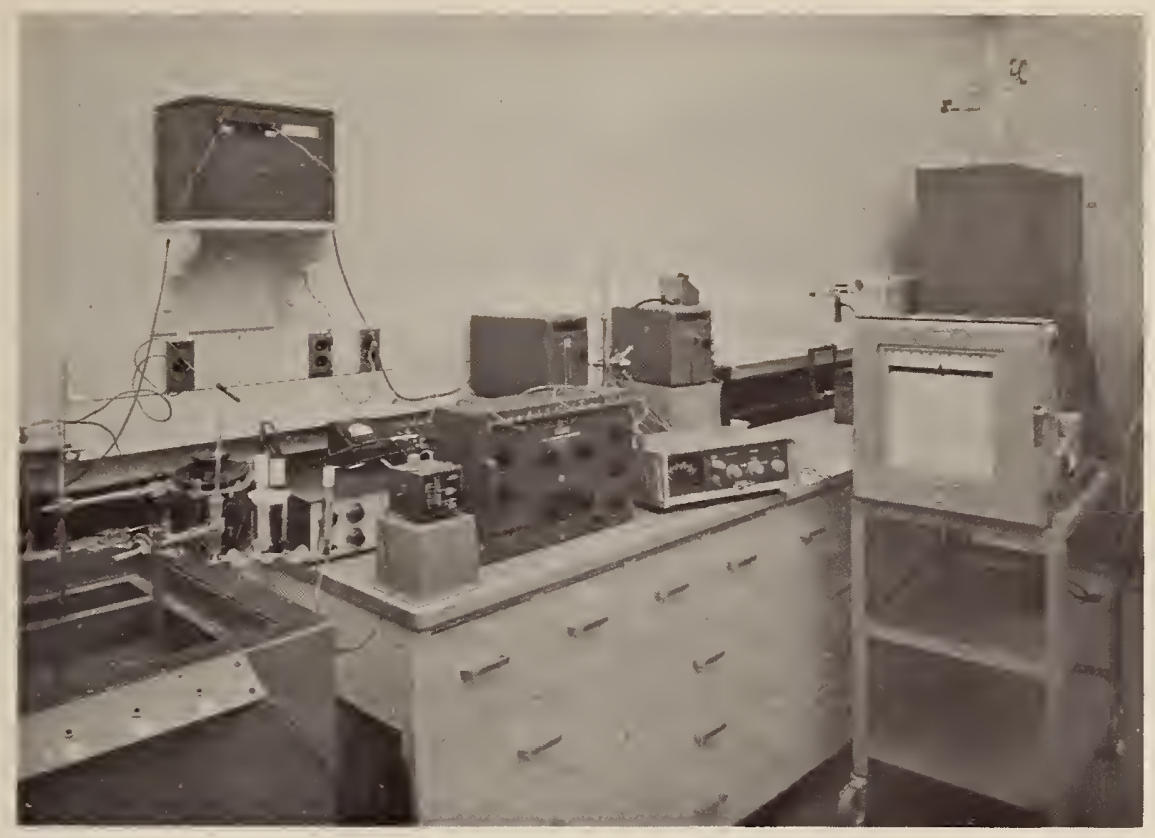

Figure 11. Equipment for emf measurements with ion-selective electrodes.

In the last column of table 9 are given standard values of - log $\gamma_{\mathrm{Na}^{+}}$obtained by combining $\gamma_{\mathrm{Cl}^{-}}$(equation 6) with the mean activity coefficients of sodium chloride in its pure aqueous solution. Strictly speaking, these should only be compared with the "observed" - log $\gamma_{\text {Nat }}$ in sodium chloride solutions. The rather satisfactory agreement with "observed" values for other sodium salt solutions, however, suggests that the ionic strength rule is at least approximately valid from $I=0.001$ to $I=0.8$.

Our planned future programs include the testing of the complete line of available ion-selective electrodes and the development of standardization procedures and standard reference solutions for their uniform calibration.

The work described was made possible by the financial support of The Foxboro Company of Foxboro, Massachusetts.

(M. Alfenaar) 
A. Thermodynamics of Hydrochloric Acid in 92.41 wt. Percent Ethanol

The past two decades have seen an increasing interest in the properties of electrolytes in mixed solvents, especially those solvents of which water is a constituent. There is now a considerable body of information on the halogen acids, limited in general to media containing at least 40 wt. percent of water. Most of this information has been derived from emf measurements of suitable cells. Measurements of the solubilities of the alkali halides in mixed solvents have also been made; these are, by their very nature, less informative than the emf studies which cover a range of solute concentrations.

The most extensive of these investigations have dealt with solvents of moderate to high dielectric constant where it is safe to assume that the electrolyte, strong in water, is completely dissociated in the mixed solvent as well. For this reason, a study of the thermodynamic behavior of hydrochloric acid in $95 \mathrm{vol}$. percent (92.4I wt. percent) ethanol by careful emf measurements in the temperature range 5 to $50{ }^{\circ} \mathrm{C}$ was undertaken. The dielectric constant of this medium is rather low ( 27.2 at $25{ }^{\circ} \mathrm{C}$ ), and it may be expected that the hydrochloric acid will not be fully dissociated. One of the aims of the study was to ascertain the effect of this ion-pair formation on the accuracy with which the standard emf of the cell and the thermodynamic constants of the acid could be obtained.

Electromotive force measurements were made of the cell

$$
\text { Pt; } \mathrm{H}_{2}(\mathrm{~g}), \mathrm{HCl}(\mathrm{m}) \text { in } 92.41 \text { wt. \% ethanol, } \mathrm{AgCl} ; \mathrm{Ag}
$$

where $\mathrm{m}$ represents molality. The expression relating the emf $\mathrm{E}$ and standard emf $\mathrm{S}^{\circ}$ (based on the standard state in 
92.41 wt. percent ethanol) can be written

$$
E={ }_{s} E^{0}-2 k \ln \left(m_{ \pm} \cdot{ }_{s} \gamma_{ \pm}\right)={ }_{s} E^{0}-2 k \ln \left(m_{ \pm}^{1} \cdot{ }_{s} \gamma_{ \pm}^{1}\right)
$$

where $m_{ \pm}$and ${ }_{S} \gamma_{ \pm}$are the stoichiometric molality and activity coefficient of hydrochloric acid, $m_{ \pm}^{\prime}$ and ${ }_{s} \gamma_{ \pm}^{1}$ are the corresponding quantities for fully dissociated hydrochloric acid, and $\mathrm{k}$ is written for RT/F. In order to derive the standard emf from measured values of $E$ over a range of $m_{ \pm}$, one can utilize the Debye-Hitckel formula for ${ }_{s} \gamma_{ \pm}^{\prime}$, but only if the ionic concentration $\mathrm{m}_{ \pm}^{\prime}$ is known. To obtain the latter, it was necessary to know the lon-pair dissociation constant in 92.41 wt. percent ethanol.

Values for the ion-pair constant in ethanol-water solvents of various compositions are avallable in the literature, but these are, in general, only known at $25{ }^{\circ} \mathrm{C}$. To obtain values at the other temperatures from that at $25{ }^{\circ} \mathrm{C}$, an equation proposed by Fuoss [26] was used. In order to calculate the actual ion concentrations and the real activity coefficient most accurately, it was found desirable to employ the "extended terms" form of the Debye-Hthckel equation. The manner in which the extended terms are applied is such that the calculations are very laborious. This difficulty was circumvented by fitting the extended terms contributions to a power series in $\mathrm{Ba} \sqrt{\mathrm{m}} \pm$, where $\mathrm{B}$ is the second Debye-Hthckel constant and a is the ion-size parameter. For a selected value of the ion-pair dissociation constant, It was then possible to program the entire calculation for solution with the aid of the time-shared computer.

By the procedure outlined above, "apparent" values of the standard emf were obtained and found to vary in nearly linear fashion with $\mathrm{m}_{ \pm}^{\prime}$, making it possible to extrapolate readily to $m_{ \pm}^{\prime}=0$. Iinearity was improved by varying the value of the ion-size parameter (a) chosen, and the best 
value was taken to be that which yielded the minimum variance from a straight line. The values of a so obtained were very reasonable (a has been found to be $4.3 \AA$ in water at $\left.25{ }^{\circ} \mathrm{C}[27]\right)$, and the fact that the variation of a with temperature is only slight lends confidence to the estimates of the ion-pair dissociation constant over the range of temperatures studied. The values of $K_{d}$, the ion-pair constant; $a$; and $\mathrm{E}^{\circ}$ at 5,25 , and $50{ }^{\circ} \mathrm{C}$ are summarized in table 10.

Table 10. Determination of the standard emf $\left({ }_{S} E^{\circ}\right)$ for the cell: Pt; $\mathrm{H}_{2}, \mathrm{HCl}(\mathrm{m})$ in 92.41 wt. \% ethanol, $\mathrm{AgCl} ; \mathrm{Ag}$ at 5,25 , and $50{ }^{\circ} \mathrm{C}$.
$t$
$\mathrm{K}_{\mathrm{d}}$
a
$S^{E^{\circ}}$

${ }^{\circ} \mathrm{C}$

$\AA$

$\mathrm{V}$

$\begin{array}{rlll}5 & 0.0436 & 4.0 & 0.10607 \\ 25 & 0.0325 & 4.1 & 0.07185 \\ 50 & 0.0214 & 4.3 & 0.02269\end{array}$

The standard emf having been determined, it was possible to calculate the stoichiometric activity coefficients for hydrochloric acid in 92.41 wt. percent ethanol by equation 10. The variation of $\log \gamma_{ \pm}$with $\mathrm{m}^{1 / 2}$ is shown in figure 12 and compared with that found earlier for water [27] and for $50 \mathrm{wt}$. percent ethanol [28]. The lower values in 92.41 percent ethanol reflect the increased interionic forces at the relatively low dielectric constant as well as the incomplete dissociation of the solute. 


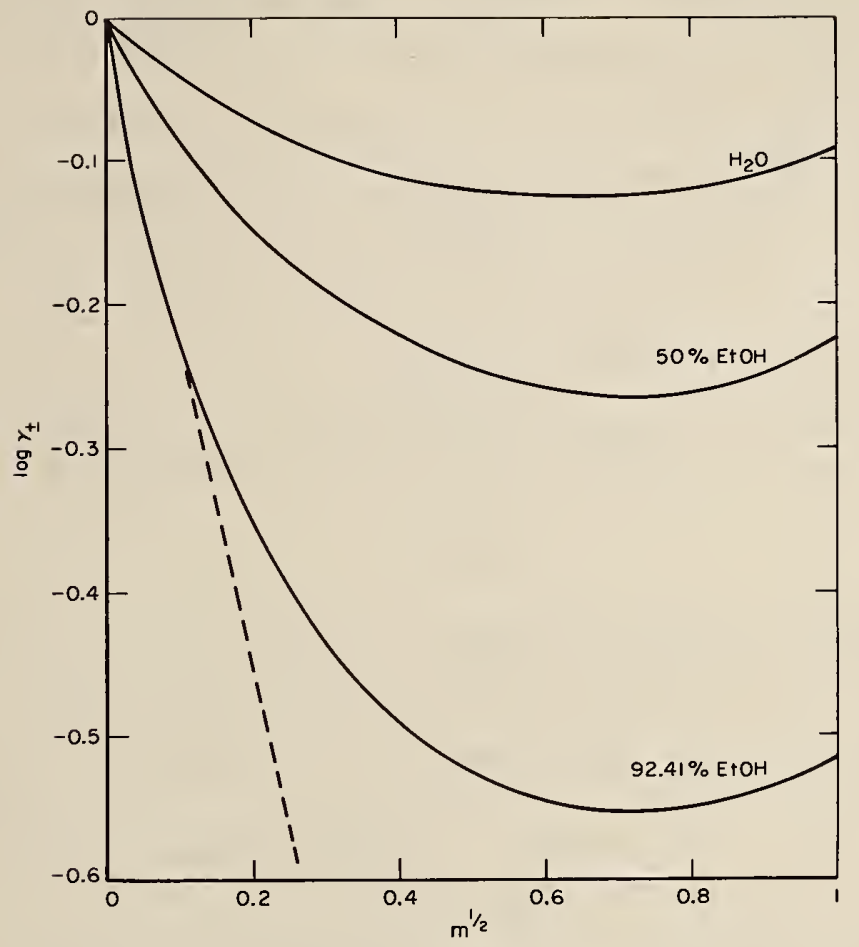

Figure 12. Variation of $\log \gamma_{ \pm}$for hydrochloric acid with the square root of the molality in $92.41 \mathrm{wt}$. percent ethanol compared with that in water and in $50 \mathrm{wt}$. percent ethanol. dotted line, Debye-Hthckel limiting slope for $92.41 \%$ ethanol

The change of $\log \gamma_{ \pm}$with temperature furnishes a means of evaluating the relative partial molal enthalpy $\left(\bar{I}_{2}\right)$ and the relative partial molal heat capacity $\left(\bar{J}_{2}\right)$ for hydrochloric acid in this mixed solvent. The values at $25^{\circ} \mathrm{C}$ for the $0.1 \mathrm{~m}$ solution in water and in $92.41 \mathrm{wt}$. percent ethanol are compared in table $l 1$. 
Table 11. Comparison of $\overline{\mathrm{I}}_{2}$ and $\bar{J}_{2}$ for hydrochloric acid (0.1 mola.1) in water and in 92.41 wt. percent ethanol at $25{ }^{\circ} \mathrm{C}$.

$$
\frac{\bar{I}_{2}}{J \operatorname{mol}^{-1}} \frac{\bar{J}_{2}}{J_{K^{-1}} \operatorname{mol}^{-1}}
$$

Water

742

13

92.41 wt. percent ethano1 8590

137

(K. H. Pool, R. G. Bates)

B. Second Dissociation Constant of Carbonic Acid in Deuterium Oxide

The dissociation constants of several weak acids in deuterium oxide $[11,12]$, as well as the ionization constant of deuterium oxide itself [29], have been determined in the Section by the emf method. These studies have now been extended to include a measurement of the second dissociation constant of deuterocarbonic acid in heavy water. This acid-base equilibrium has not been thoroughly investigated, and existing values for the dissociation constant at $25{ }^{\circ} \mathrm{C}$ differ considerably $[30,31]$.

The dissociation constant was determined from 5 to $50{ }^{\circ} \mathrm{C}$ by measuring the emf of the cell

$$
\text { Pt; } \mathrm{D}_{2}(\mathrm{~g}), \mathrm{NaDCO}_{3}(\mathrm{~m}), \mathrm{Na}_{2} \mathrm{CO}_{3}(\mathrm{~m}), \mathrm{NaCl}(\mathrm{m}) \text { in } \mathrm{D}_{2} \mathrm{O}, \mathrm{AgCl} ; \mathrm{Ag}
$$


The molality (m) of each carbonate was kept equal to that of the sodium chloride in all of the cell solutions; $m$ was varied from 0.003 to $0.03 \mathrm{~mol} \mathrm{\textrm {kg } ^ { - 1 }}$

An expression relating the "apparent" dissociation constant $\mathrm{K}_{2}^{1}$ to the emf $\mathrm{E}$ of the cell was obtained by combining the mass law with the Nernst equation for the emf:

$$
\mathrm{pK}_{2}^{\prime}=\frac{E-E^{\circ}}{\mathrm{k}}+\log \mathrm{m}_{\mathrm{CI}}-\log \frac{\mathrm{DCO}_{3}^{-}+[\mathrm{OD}-]}{\mathrm{m}_{\mathrm{CO}_{3}^{=}}-\left[\mathrm{OD}^{-}\right]}+\frac{2 \mathrm{AI}^{1 / 2} \mathrm{~d}_{0}^{1 / 2}}{1+\mathrm{BaI}^{1 / 2} \mathrm{~d}_{0}^{1 / 2}}
$$

where $\mathrm{E}^{\circ}$ is the standard emf of the cell, $\mathrm{k}$ is (RT In 10)/F, $A$ and $B$ are the Debye-Hitckel constants in deuterium oxide, I is the ionic strength, a is the ion-size parameter, and $d_{0}$ is the density of heavy water. The small correction for hydrolysis was made by estimating the deuteroxide ion concentration from the emf and the self-dissociation constant of deuterium oxide.

The value of $\mathrm{pK}_{2}$, that is, the limit of $\mathrm{pK}_{2}^{1}$ at $I=0$, was obtained by fitting the data to an equation linear in I by the method of least squares. A plot of the data at $25{ }^{\circ} \mathrm{C}$ is shown in figure 13. The values of $\mathrm{pK}_{2}^{l}$ from one series are consistently higher than the results from the other two series. This is presumed to have been caused by a small amount of tritium in the heavy water used for this run, as this lot of solvent had a radioactivity of about $0.4 \mu \mathrm{C} 1 / \mathrm{cm}^{3}$.

The results of this series were not used in the final calculation of $\mathrm{pK}_{2}$. Instead, another run was made with heavy water that had a relatively low activity of about $0.14 \mu \mathrm{Ci} / \mathrm{cm}^{3}$ (see Section 2.D.3). The values of $\mathrm{pK}_{2}$ found were identical with those of two earlier runs within the limits of experimental error. 


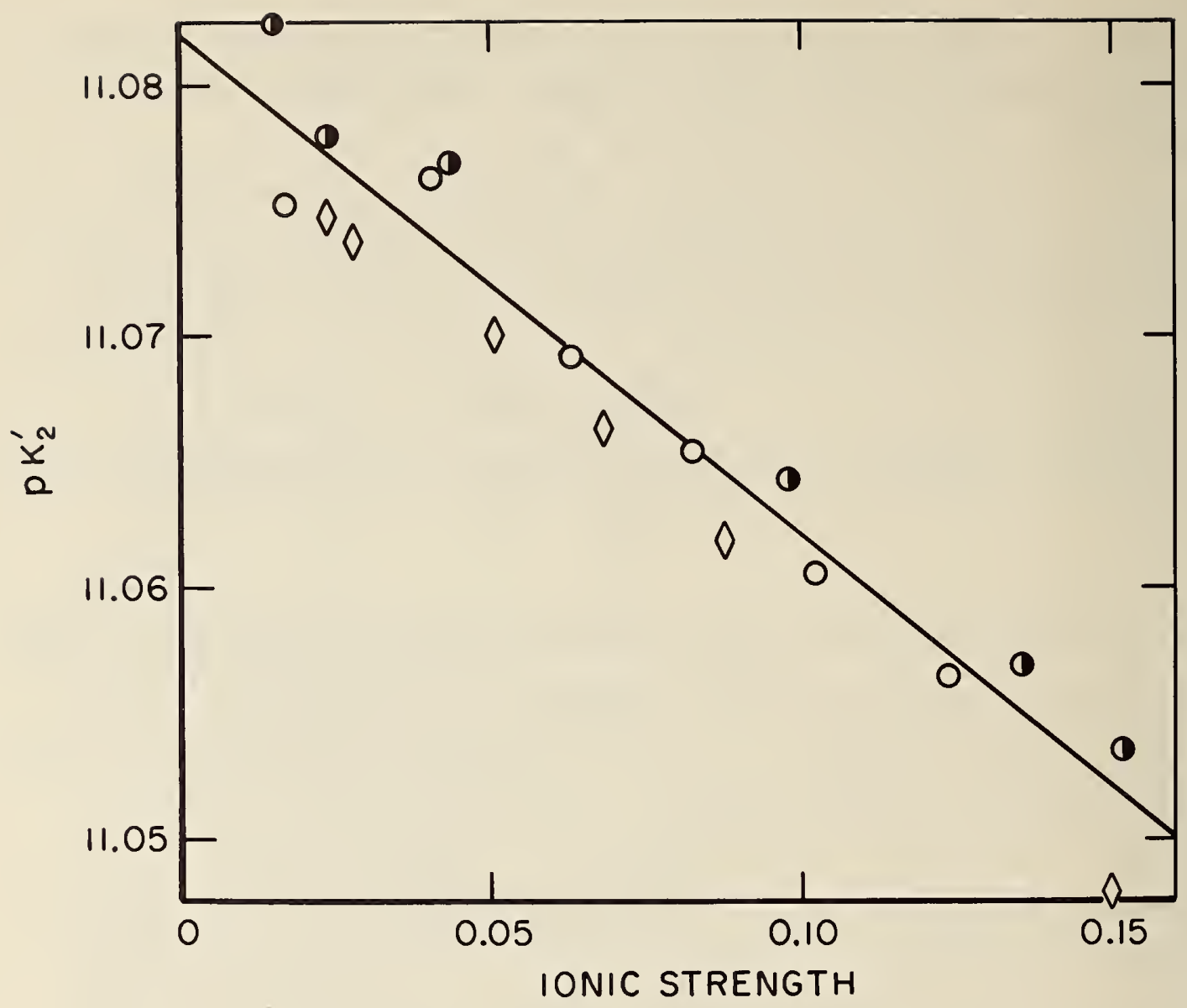

Figure 13. Determination of $\mathrm{pK}_{2}$ for deuterocarbonic acid at $25{ }^{\circ} \mathrm{C}$.

Several different values of the ion-size parameter were used in the calculations of $\mathrm{pK}_{2}^{\prime}$, and that which gave the smallest standard deviation in $\mathrm{pK}_{2}$ was selected. In this way, the ion-size parameter was found to vary from $6.0 \AA$ at $5{ }^{\circ} \mathrm{C}$ to $7.2 \AA$ at $50{ }^{\circ} \mathrm{C}$. The $\mathrm{pK}_{2}$ values (molal scale) found are listed in table 12. The value at $25{ }^{\circ} \mathrm{C}(11.077)$ is to be compared with 10.85 found by Curry and Hugus [30] and with 11.00 of Glasoe and Long [31]. 
Table 12. Dissociation of the deuterocarbonate ion $\left(\mathrm{DCO}_{3}{ }^{-}\right)$ in deuterium oxide from 5 to $50{ }^{\circ} \mathrm{C}$.
$t,{ }^{\circ} \mathrm{C}$
$\mathrm{pK}_{2}$
$t,{ }^{\circ} \mathrm{C}$
$\mathrm{pK}_{2}$

$\begin{array}{rlll}5 & 11.332 & 30 & 11.028 \\ 10 & 11.259 & 35 & 10.984 \\ 15 & 11.192 & 40 & 10.945 \\ 20 & 11.132 & 45 & 10.911 \\ 25 & 11.077 & 50 & 10.882\end{array}$

(M. Paabo)

C. Properties of Acids and Bases in Hydrogen-Bonded Mixed Solvents

Binary mixed solvents which contain water as one component react protolytically both with hydrogen acids and with their conjugate bases. Although the acid-base behavior of many of these solvent mixtures resembles that of water in kind, wide differences of degree are observed.

During the past year a comprehensive review of the equilibrium properties of acids and bases in amphiprotic mixed solvents was prepared. The effect of adding an organic constituent to aqueous solutions of acids and bases was examined through summaries of data for standard electromotive forces, equilibrium constants, medium effects, and thermodynamic functions for the transfer of weak and strong electrolytes from water to mixed solvents of various compositions. Systems consisting of strong and weak electrolytes in mixed solvents were considered. 
The solvent effect on an acid-base equilibrium depends strongly on the charge type of the acid and its conjugate base. The change in dielectric constant produced by altering the composition of the solvent also has a large influence. Other factors tending to shift the equilibrium are more difficult to identify. In general, they may be classified as secondary solute-solute interactions and solutesolvent interactions. Any side reaction capable of altering the free energy of one or more of the participants in the primary equilibrium will evidently contribute to the solvent effect. Ion-solvent interactions, in particular, are influenced by hydrogen-bonding capability, the formation of ion pairs and higher aggregates, sorting of the two types of solvent molecules by the ions, and alterations of solvent basicity. In the water-like region of relatively high dielectric constant, solvent effects show a considerable uniformity that disappears as the solvent becomes rich in the organic constituent.

There is a growing realization that the structure of water and of the mixed solvents themselves plays a primary role in altering the equilibrium properties of acids and bases in mixed solvents. In evaluating solvent effects, attention is usually focused on the change in free energy and its relation to the solvent composition. It is now evident that free energy changes of this sort are the resultant of large changes in enthalpy and entropy. This may be seen in figure 14, where the changes in $\Delta G^{\circ}, \Delta H^{\circ}$, and $T \Delta S^{\circ}$ for the transfer of a mole of hydrochloric acid from the standard state in water to the standard state in ethylene glycol-water solvents are plotted as a function of the composition of the solvent mixture. It is also true for the dissociation process of a weak acid, as shown in figure 15. In this figure, the thermodynamic functions for the process, 


$$
\mathrm{H}^{+}(\mathrm{w})+\mathrm{Ac}^{-}(\mathrm{w})+\mathrm{HAc}(\mathrm{s})=\mathrm{H}^{+}(\mathrm{s})+\mathrm{Ac}^{-}(\mathrm{s})+\mathrm{HAc}(\mathrm{w})
$$

in which acetic acid (HAc) is transferred from water (w) to a series of ethanol-water mixtures ( $\mathrm{s}$ ), are plotted as a function of the solvent composition. The values of these energy quantities are shown in kilocalories; $1 \mathrm{kcal}=$ $4.184 \mathrm{~kJ}$.

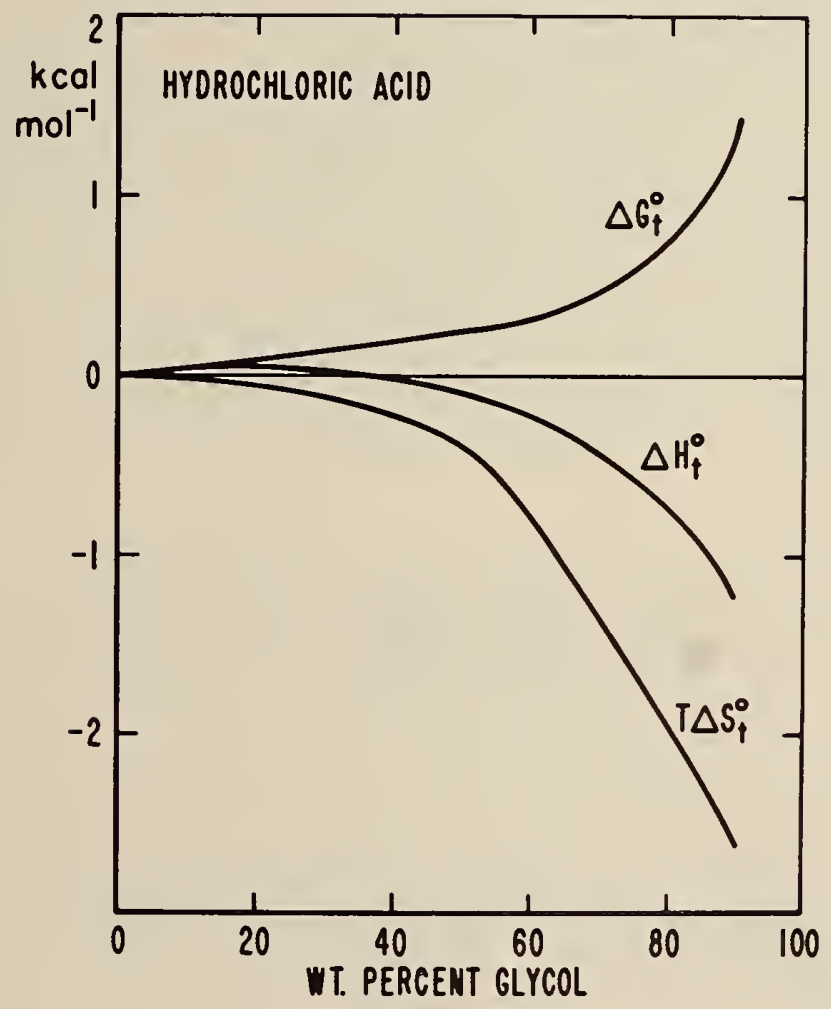

Figure 14. Standard thermodynamic functions for the transfer of hydrochloric acid from water to ethylene glycol-water solvents at $25{ }^{\circ} \mathrm{C}$. 


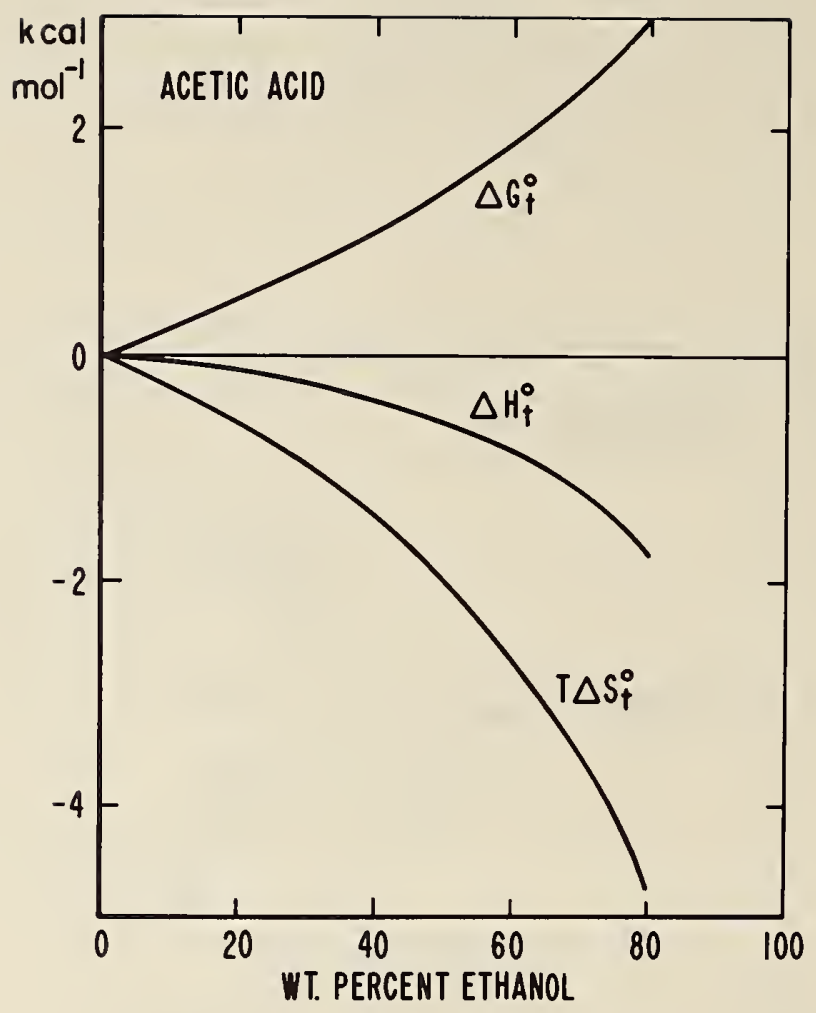

Figure 15. Standard thermodynamic functions for the transfer of acetic acid from water to ethanol-water solvents at $25{ }^{\circ} \mathrm{C}$.

These conclusions were presented in a plenary lecture at the Symposium on Equilibria and Reaction Kinetics in Hydrogen-Bonded Solvent Systems held at the University of Newcastle upon Tyne (England) in January. This international meeting was arranged in recognition of the retirement of Lord Wynne-Jones from the position of head of the department of physical chemistry at Newcastle upon Tyne.

$$
\text { (R. G. Bates) }
$$


6. CONDUCTANCE AND TRANSPORT BEHAVIOR OF ELECTROLYTES

A. Oceanographic Conductance Standards

The oceanographer uses salinity determinations for two main purposes: to identify and trace water masses and as a starting point for computing other properties such as the density and sound velocity. At present, salinity determinations are made almost entirely by conductometric methods, and for maximum usefulness the conductance should be known to $50 \mathrm{ppm}$ [32]. This requirement places the oceanographic needs at the very forefront of developing techniques, since very few research measurements of conductance have been made with a standard error less than 200 ppm. Equipment with the requisite sensitivity has been developed for salinity determinations, and high precision is obtained either by frequent calibration with a standard or by a differential method in which the unknown is compared directly with a standard.

The internationally accepted standard for this purpose is natural sea water that has been carefully certifled for chlorinity. Standards corresponding to other salinities are urgently needed, and it seems advisable to relate them to a single pure electrolyte so that there is a direct relationship between conductivity and a chloride assay or the welght of solid electrolyte. For the above reasons, the section has initiated a program to develop as standards solutions of $0.5,1,2$, and 4 percent sodium chloride in water. The specific conductance of these solutions at 15 and $25{ }^{\circ} \mathrm{C}$ will be certified.

\section{B. Apparatus}

The major new item of equipment is the transformer ratio-arm conductivity bridge shown in figure 16. This instrument is based on the design of Janz and McIntyre [33] and is built around a commercial impedance comparator. 


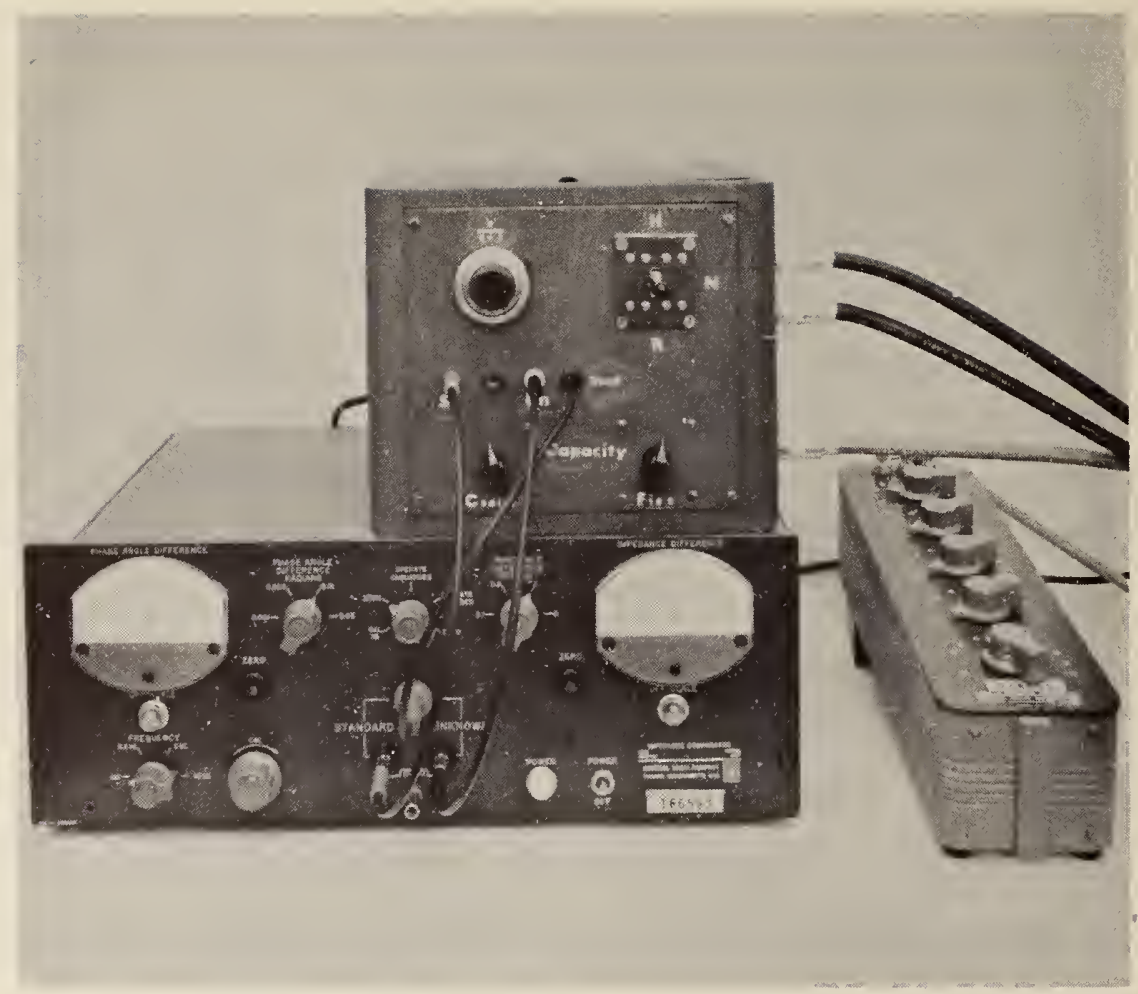

Figure 16. Janz-McIntyre conductivity bridge.

The cabinet shown on top of the comparator in the figure contains switches for use with four-terminal cells in order to eliminate the effects of lead resistance, and it also contains the variable capacitors needed to equalize the phase angle of the standard and unknown impedances.

The major departures from the recommendations of Janz and McIntyre are the selection of a more sensitive model of comparator and a narrower range of frequencies. This instrument can indicate an unbalance of impedance of $10 \mathrm{ppm}$, and the specified accuracy is $30 \mathrm{ppm}$. When highquality resistors were interchanged between the Reference, and Standard connections of the bridge, no inequality of 
the ratio arms was detectable. The comparator was specially modified to provide frequencies of $1,2.5,5$, and $10 \mathrm{kHz}$. Within this range, the a-c impedances of the coils used as standard resistors differ negligibly from the d-c calibration values.

Some conductivity cells of a demountable design are shown in figure 17. The heart of the design is the quartz body, which has optically flat and parallel ends and a precisely-ground cylindrical interior. The cells are closed by plane electrodes made of platinum sheet soldered with pure tin to quarter-inch stainless steel plates for rigidity. Tests are in progress to determine the reproducibility of the cell constants as the cells are taken apart and reassembled, but it is hoped that the constant can be determined absolutely from the dimensions of the quartz cylinder with an uncertainty less than $50 \mathrm{ppm}$.

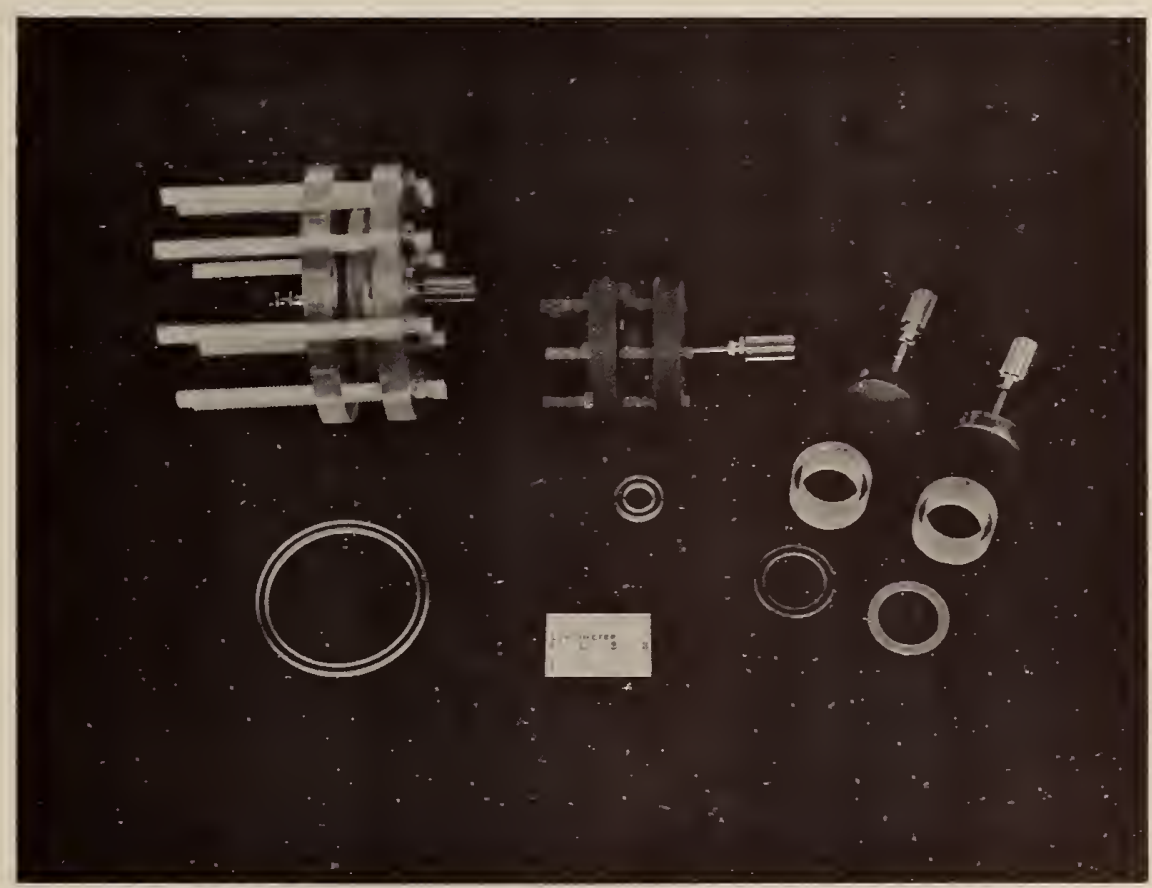

Figure 17. Demountable conductivity cells. 
The parts shown in figure 17 provide cell constants of $0.02,0.03,0.48$, and $0.51 \mathrm{~cm}^{-1}$. Additional bodies are being prepared to give constants of 7.6 and $30.6 \mathrm{~cm}^{-1}$. Experience thus far indicates that aqueous solutions and many nonaqueous solutions can be contained in the cells without the use of gaskets or seals. One interesting application of one of these cells is described in the next section of this report. The glass cells of conventional design and large constant (10, 35, and $100 \mathrm{~cm}^{-1}$ ) have been constructed for use in the work on oceanographic conductance standards.

\section{(T. B. Hoover)}

C. Characteristics of "Azulene Periodate"

A conductometric characterization of an azulene derivative, believed to be a polymeric electrolyte, was requested by the Organic Chemistry Section. Only $3 \mathrm{mg}$ of the material (in the form of a nearly saturated solution in $5 \mathrm{~cm}^{3}$ of dimethylformamide) could be supplied. Iess than $2 \mathrm{~cm}^{3}$ of this stock solution was actually used for the following measurements.

The specific conductivities of the stock solution and of three dilutions were measured in the smaller assembled cell shown in figure 17. This cell has a constant of $0.509 \mathrm{~cm}^{-1}$ and a volume of $0.314 \mathrm{~cm}^{3}$. The major limitation of the measurements was the relatively high specific conductance of the solvent used to prepare the original solution. The solvent correction amounted to 10 percent in the case of the stock solution and 25 percent for the third dilution.

A "solute specific conductance" was calculated for concentration units in grams per liter and was extrapolated as a function of the square root of the concentration to 
give a limiting value not less than $0.31 \mathrm{~g}^{-1} \Omega^{-1}$. This latter value established an upper limit of 320 for the equivalent weight of the unknown material, since all electrolytes whose conductances have been measured in dimethylformamide have limiting equivalent conductances less than $951 \mathrm{~mol}^{-1} \Omega^{-1}$. The slope of the plot of the "solute specific conductance" Vs. the square root of the concentration was also much greater than reasonable estimates of the limiting Fuoss-Onsager slope for the same solvent. The experimental results were not consistent with the hypothesis that the specimen was a strong electrolyte nor that a strong electrolytic impurity was being observed. They conformed, however, fairly well with those expected for a weak electrolyte having $\mathrm{pK}_{\mathrm{d}}$ between 3 and 4 . The $\mathrm{pK}_{\mathrm{d}}$ for the dissociation of ion pairs in dimethylformamide is near 2 for several salts [34], so that it may be concluded that the azulene derivative is a moderately weak electrolyte.

(T. B. Hoover)

\section{Hydrodynamic Properties of Ions}

The parameters which determine the mobility of an ion in an electric field have been of concern almost since the beginnings of lonic theory. Ideally, one would like to be able to separate the factors into those characteristic of the solvent and others characteristic of the ion. The extremely useful Walden rule, in combination with the Stokes law, states that the limiting equivalent conductance is inversely proportional both to the solvent viscosity and to the lonic radius. Fuoss observed, from extensive studies in binary solvent systems, that the Walden product (viscosity times equivalent conductance) varies systematically with dielectric constant and offered the explanation of dielectric friction [35]. This friction is the retarding 
force on an ion, in addition to stokes friction, that results from the energy dissipation in reorienting solvent dipoles around the moving charge. By heuristic arguments, Fuoss arrived at an equation of the form

$$
1 /\left(\eta_{0} \lambda_{0}\right) \propto R_{0}+A / D
$$

where $\eta_{0}$ and $D$ are the viscosity and dielectric constant of the solvent, $\lambda_{\circ}$ is the limiting equivalent conductance of an ion, and $R_{0}$ is its "Stokes" radius. He suggested empirically that the constant $A$ was approximately $36 / \mathrm{R}_{0}$ in aprotic solvents and nearly $4 R_{0}$ when one component of the solvent is hydrogen-bonding.

A rigorous derivation of equation 12 for a dielectric continuum model of the solvent was given by Zwanzig [36]. The term A turned out to be proportional to $\tau / \mathrm{R}_{0}^{3}$, where $\tau$ is a third solvent parameter, the dielectric relaxation time. When applied to experimental data, the Zwanzig equation runs into inconsistencies that may be best expressed by saying that most solvents have dielectric relaxation times differing by more than an order of magnitude from the values required by the conductance data.

Since the weakness of the Zwanzig treatment may derive from the dielectric continuum model, the application of the Eyring reaction rate theory to conductance is being explored in the Section. Eyring's model considers discrete solvent molecules which are comparable in size to the ions. A key parameter in his treatment of conductance or viscosity is the characteristic jump distance of the solvent. Following the explanation of Fuoss, it is plausible that a major part of the activation energy for conductance should be the electrostatic energy of the dielectric atmosphere, which must be reoriented at each jump of the ion to a new vacancy. 
This step leads directly to an exponential form of equation proposed by Mezhennil [37] for the variation of the Walden product with dielectric constant:

$$
\eta_{0} \lambda_{0} \propto R_{0} \exp (-S / D)
$$

Empirically, equation 12 and equation 13 seem equally satisfactory.

Rough estimates have been obtained for the parameters of equation 13 for six electrolytes whose conductances have been measured in six or more pure aprotic solvents. The values of $R_{0}$ were all smaller than the crystallographic radil of the ions; $S$ values for the anions were all negative but probably not significantly different from zero, while the corresponding parameters for the cations showed larger, positive values and appreciable differences. The dielectric energy of the region surrounding an ion is independent of the sign of the charge on the central ion, so the distinction between anions and cations may have its source in an entropy of activation. Minc and Werblan [38] have measured the entropy of activation for conductance for several electrolytes in acetonitrile and have found that this quantity is correlated with solvation energies, being positive for small cations and negative for perchlorate and tetraethylammonium ions.

The numerical results obtained thus far are so tentative that very little importance can be attached to them, but the approach gives promise of providing a fresh insight into the hydrodynamic behavior of ions in various solvents.

(T. B. Hoover) 
A. Propylene Carbonate

Due to its relatively high dielectric constant $(64.4$ at $25{ }^{\circ} \mathrm{C}$ ) and good solvent properties, propylene carbonate is rapidly gaining favor for electrochemical studies. The following method of purification was devised by combining useful features of several proposed methods [39], at the same time eliminating unnecessary steps.

The commercial propylene carbonate was dried overnight with molecular sieves and then distilled twice. The initial 150 to $200 \mathrm{~cm}^{3}$ of distillate from the first distillation of about 31 was discarded. The major fraction, distilled at 106 to $109{ }^{\circ} \mathrm{C}$ under a pressure of 7 to 8 torr, was collected for use. The product had a specific conductivity of between $3 \times 10^{-7}$ and $8 \times 10^{-7} \Omega^{-1}$. A second distillation at 114 to $116{ }^{\circ} \mathrm{C}$ and 4 to 5 torr yielded a product having a specific conductivity of $2 \times 10^{-8}$ to $4 \times 10^{-8} \Omega^{-1}$. It was believed to be of sufficient purity for emf studies.

Further work on the characterization of pure propylene carbonate is under way. In addition, the properties of the 50 wt. percent mixture of methanol and propylene carbonate will be determined over a range of temperatures. These properties will include dielectric constant, vapor pressure, and density.

$$
\text { (B. R. Staples) }
$$

B. Cryoscopic Behavior of N-Methylpropionamide

Because of its remarkably high dielectric constant (about 175 at room temperature) and useful solvent properties, N-methylpropionamide is of interest in the Section for electrochemical and kinetic studies. As part of a characterization program, the freezing point and cryoscopic 
constant of this solvent were determined. A 50-g sample was frozen, with mechanical stirring, in a dewar flask while protected from atmospheric moisture by a stream of dry nitrogen. The temperature was measured with a calibrated platinum resistance thermometer and Mueller bridge. The unbalance of the bridge was amplified and continuously recorded on a chart recorder. Heat was abstracted at a rate of approximately $2 \mathrm{~J} / \mathrm{s}$ and the run was continued until nearly one-third of the charge had frozen, when the mixture became too stiff for effective stirring. This limitation prevented a cryoscopic determination of sample purity, but the specimen was representative of the best material that had been used for conductance and dielectric constant measurements.

The cryoscopic constant was determined by measuring the lowering of the freezing point produced by known additions of $\mathrm{N}$-methylacetamide. This solute has a freezing point about $60^{\circ} \mathrm{C}$ higher than that of the solvent, but it should form nearly ideal solutions with $\mathrm{N}$-methylpropionamide because of the close chemical similarity of the two compounds. The results are summarized in table 13. The cryoscopic constant of $4.68 \mathrm{deg} \mathrm{kg} / \mathrm{mol}$ found for $\mathrm{N}$-methylpropionamide corresponds to a heat of fusion of $9.2 \mathrm{~kJ} / \mathrm{mol}$. This quantity apparently has never been measured calorimetrical1y.

Table 13. Freezing point and cryoscopic constant of $\mathrm{N}$-methylpropionamide.

\begin{tabular}{|c|c|c|c|c|}
\hline 0 & 0 & 0.0425 & 0.1658 & 0.2216 \\
\hline .917 & -30.920 & -31.152 & -31.695 & -31.958 \\
\hline - & - & 4.681 & 4.674 & 4.685 \\
\hline
\end{tabular}




\section{FOREIGN-CURRENCY PROGRAMS}

The two projects sponsored by the Electrochemical Analysis Section at universities in India and financed through the provisions of Public Law 480 continued active during the reporting year. A brief description of these programs follows.

Properties of Electrolytes in Nonaqueous Media, Jadavpur University, Calcutta. Dr. M. N. Das and Dr. K. K. Kundu.

(a) Dissociation constants and related thermodynamic quantities for acetic acid in ethylene glycol and propylene glycol over the temperature range 5 to $45^{\circ} \mathrm{C}$ were determined.

(b) The standard potential of the silver-silver bromide electrode in propylene glycol was determined from 5 to $45^{\circ} \mathrm{C}$.

(c) Standard potentials of the silver-silver bromide electrode in isodielectric media formed by mixing methanol with propylene glycol were determined at $25{ }^{\circ} \mathrm{C}$.

(d) The standard free energy change on the transfer of sodium bromide from water to isodielectric mixtures of methanol and propylene glycol was measured at $25{ }^{\circ} \mathrm{C}$.

(e) The acidic dissociation constants of ammonium ion, diethylammonium ion, and triethylammonium ion were determined in ethylene glycol over the temperature range 5 to $45^{\circ} \mathrm{C}$.

Physicochemical Studies in Nonaqueous Solvents, Panjab University, Chandigarh. Professor R. C. Paul.

The current work under way in Professor Paul's laboratory includes studies of ion-solvent processes and the behavior of Lewis acids in media of limited hydrogen-bonding capability. Studies of ion-pair formation and the dissociation of weak electrolytes using conductance techniques are also of interest.

(R. G. Bates) 
9. REVIEWS, CONFERENCES, AND COMIITTEE ACTIVITY

Three reviews on specialized topics in solution chemistry were prepared during the year. The first, co-authored with W. J. Waddell, dealt with intracellular $\mathrm{pH}$ and was prepared for publication in Physiological Reviews. The second was based on a lecture given at an international symposium on intracellular glass microelectrodes (Montreal, May 1967) and bore the title "Inner Reference Electrodes". The third was prepared for presentation as a plenary lecture at an international symposium on "Equilibria and Reaction Kinetics in Hydrogen-Bonded Solvent Systems" (Newcastle, January 1968) [see Section 5.C]. A monograph "Acid-Base Behavior in Aprotic Organic Solvents" by M. M. Davis will be published shortly in the NBS Monograph Series. Three articles on $\mathrm{pH}$ measurement were prepared for forthcoming handbooks and encyclopedias.

Considerable work on nomenclature, terminology, and units was done under the auspices of the U.S. National Committee for ISO/TC-12, the IUPAC Commission on Symbols, Terminology, and Units, and two committees of the U.S.A. Standards Institute. The IUPAC activity culminated at the Prague Conference (August 1967) where a draft of the new manual of symbols and units was completed.

A revised draft of an ASTM standard on $\mathrm{pH}$ measurement was prepared.

(R. G. Bates) 
The impact of the Section's activities can best be judged in terms of the distribution of Section publications, invited talks, and requests for advice and consultation. In this connection, the following statistics, compiled for the calendar year 1967 unless otherwise indicated, are pertinent.

Reprints requested . . . . . . . 881

Manuscripts reviewed for outside journals... . . . . 30

Project proposals, books reviewed . . . . . . . . 5

Significant consultations . . . . . 30 universities industries federal and state agencies 15

Committee memberships . . . . . . 18 Publications $(7 / 67$ to $6 / 68)$. . . . . 12 Talks $(7 / 67$ to $6 / 68)$......... 15 scientific societies 6 universities industries 


\section{PERSONNEL}

Roger G. Bates, Section Chief

Marguerite Raudenbush, Section Secretary

Conductance Mea.surements

T. B. Hoover

Electromotive Force and

Acidity Measurements

Aqueous solutions,

mixed solvents

B. R. Staples

Heavy water,

mixed solvents

M. Paabo

K. H. Pool (July to Sept.) from Washington State University, Pullman

Nonaqueous solvents

E. S. Etz (July to Sept.) from Clarkson College of Technology

Ion-specific electrodes M. Alfenar (oct. to June) from University of Utrecht, Holland

Consultant

D. Rosenthal, Clarkson College of Technology 
R. G. Bates

Member, Subcommittee on Hydrogen Ion Determinations, ASTM Committee E-1, Sub. 22.

Councilor, American Chemical Society,

representing the Division of Analytical Chemistry.

Member, NRC Committee on Symbols, Units, and

Terminology for the Physical Sciences

(U.S. National Committee for ISO/TC-12).

Member, U.S. National Committee for IUPAC.

Member, Commission on Electrochemistry, IUPAC.

Member, Commission on Symbols, Terminology, and Units, IUPAC.

Associate Member, Commission on Electroanalytical Chemistry, IUPAC.

Member, Subcommittee on Physicochemical Symbols and

Terminology, Committee on Physical Chemistry, NRC.

Member, Committee YI, Abbreviations for Science

and Engineering; U.S.A. Standards Institute.

Member, Committee Y1O, Letter Symbols, U.S.A.

Standards Institute.

Member, Board of U.S. Civil Service Examiners

(Chemistry Pane1).

Member, Advisory Board for Analytical Chemistry.

Member, Board of Editorial Advisers, Analytica.

Chimica Acta.

Member, Washington Editorial Review Board (NBS);

deputy chairman.

Member, Museum Committee (NBS).

Member, Advisory Committee on the Senior Iunch Club $(\mathrm{NBS})$.

T. B. Hoover

Member, Community Services Committee, Chemical Society of Washington.

Member, Audit Committee, D.C. Chapter, Society of the Sigma X1. 
13. PUBLICATIONS AND MANUSCRIPTS, JULY 1967 TO JUNE 1968

1. Bates, R.G., (Ed.)

Electrochemical Analysis Section: Summary of Activities, July 1966 to June 1967.

NBS Tech. Note 423 (1967).

2. Robinson, R.A.

The Dissociation Constants of Some Substituted

Nitrophenols in Aqueous Solution at $25{ }^{\circ} \mathrm{C}$.

J. Res. Nat. Bur. Stand., 71A, 385-389 (1967).

3. Hetzer, H.B., Robinson, R.A., Bates, R.G.

Conventional $\mathrm{pa}_{\mathrm{H}}$ Values for Buffer Solutions of

Piperazine Phosphate from $0^{\circ}$ to $50^{\circ} \mathrm{C}$.

Anal. Chem., 40, 634 (1968).

4. Bates, R.G., Covington, A.K.

Behavior of the Glass Electrode and other

pH-Responsive Electrodes In Biological Media.

Ann. N.Y. Acad. Sci., 148, 67-80 (1968).

5. Bates, R.G.

Book Review-- "Titrations in Nonaqueous Media"

by W. Huber.

Anal. Chem., 40, IIIA (1968).

6. Covington, A.K., Paabo, M., Robinson, R.A.,

Bates, R.G.

Use of the Glass Electrode in Deuterium Oxide and the Relation between the Standardized $\mathrm{pD}$ ( $\mathrm{pa}$ )

Anal. Chem., 40, 700-706 (1968).

7. Bates, R.G.

Standardization of Acldity Measurements. Extension of the pH Concept to Mixed Solvents and Heavy Water. Anal. Chem., 40, 28A-38A (May 1968).

8. Schindler, P., Robinson, R.A., Bates, R.G.

Solubility of Tris(hydroxymethyl)aminomethane in

Water-Methanol Solvent Mixtures and Medium Effects

In the Dissociation of the Protonated Base.

J. Res. Nat. Bur. Stand., 72A, 141-148 (1968).

9. Hetzer, H.B., Robinson, R.A., Bates, R.G.

Dissociation Constants of Piperazinium Ion and

Related Thermodynamic Quantities from 0 to $50{ }^{\circ} \mathrm{C}$.

J. Phys. Chem., 12, 2081-2086 (1968). 
10. Bates, R.G.

Measurement of pH

Handbook of Biochemistry, Chemical Rubber Co. (1968).

11. Robinson, R.A., Covington, A.K.

The Thermodynamics of the Ternary System:

Water-Potassium Chloride-Calcium Chloride at $25^{\circ} \mathrm{C}$.

J. Res. Nat. Bur. Stand., 72A, 239-245 (1968).

12. Bates, R.G.

Book Review--"Glass Electrodes for Hydrogen and

Other Cations" by G. Eisenman (Ed.)

The American Scientist, 56, 148A (1968).

13. Davis, M.M.

Acid-Base Behavior in Aprotic Organic Solvents.

NBS Monograph 105. (In press).

14. Bates, R.G.

Medium Effects and $\mathrm{pH}$ in Nonaqueous Solvents

Chapter for "Solvation Interactions"

(C.D. Ritchie and J. F. Coetzee, Eds.)

Marcel Dekker, publisher. (In press).

15. Bates, R.G.

Hydrogen Ions

Encyclopaedia Brittanica. (In press).

16. Bates, R.G.

Inner Reference Electrodes and Their Characteristics Chapter in "Intracellular GIass Microelectrodes" (M. Lavallée and N. Hebert, Eds.)

John Wiley and Sons, New York, N.Y. (In press).

17. Bates, R.G.

Equilibrium Properties of Acids and Bases in Amphiprotic Mixed Solvents.

Chapter in "Equilibria and Reaction Kinetics in Hydrogen-Bonded Solvent Systems"

(A. K. Covington and P. Jones, Eds.) (In press).

18. Hoover, T.B.

The N-Methylpropionamide-Water System. Densities and Dielectric Constants at 20 to $40^{\circ}$.

J. Phys. Chem. (In press).

19. Waddell, W.J., Bates, R.G.

Intracellular pH.

Physiological Reviews. (In press). 
1. Hoover, T.B., "N-Methylpropionamide-Water Systems. Densities and Dielectric Constants", American Chemical Society, Chicago, Illinois, September 14, 1967.

2. Bates, R.G., "Equilibrium Properties of Acids and Bases in Amphiprotic Mixed Solvents", in Symposium on Equilibria and Reaction Kinetics in HydrogenBonded Solvent Systems, University of Newcastle upon Tyne, England, January 11, 1968.

3. Bates, R.G., "Meaning and Standardization of $\mathrm{pH}$ Measurements", Unilever Research Laboratory, Port Sunlight' (Cheshire), England, January 15, 1968.

4. Bates, R.G., "Meaning and Standardization of $\mathrm{pH}$ Measurements", UnIlever Research Laboratory, Bedford, England, January 16, 1968.

5. Bates, R.G., "Acldity Measurements in Mixed Solvent Systems", Chemistry department seminar, Drexel Institute of Technology, Philadelphia, Pa., January 25, 1968.

6. Bates, R.G., "Acid-Base Behavior in Hydrogen-Bonded Mixed Solvent Systems", Iowa State University, Ames, Iowa, March 7, 1968.

7. Bates, R.G., "Acid-Base Behavior in Hydrogen-Bonded Mixed Solvent Systems", Chemistry department seminar, University of Arizona, Tucson, Arizona, March 28, 1968.

8. Bates, R.G., "Acid-Base Behavior in Hydrogen-Bonded Mixed Solvent Systems", Chemistry department seminar, University of California at Santa Cruz, California, March 29, 1968.

9. Staples, B.R., "The Kinetics of Proton Transfer Reactions Determined by the Second Wien Effect", (paper by Bert R. Staples and Gordon Atkinson), American Chemical Society Meeting, San Francisco, Calif., Apri1 2, 1968.

10. Paabo, M., "Standardization of a pD Scale", (paper by Maya Paabo and Roger G. Bates), American Chemical Society Meeting, San Francisco, Calif., April 3, 1968. 
11. Staples, B.R., "Two New Standards for the pH Scale", (paper by Bert R. Staples and Roger G. Bates), American Chemical Society Meeting, San Francisco, Calif., Apri1 3, 1968.

12. Pool, Karl H., "Thermodynamics of Hydrochloric Acid in $95 \mathrm{Vol}$. \% (92.41 Wt. \%) Ethanol from E.m.f. Measurements at 5 to $50^{\circ} \mathrm{C} "$, (paper by Karl H. Pool and Roger G. Bates), American Chemical Society Meeting, San Francisco, Calif., April 5, 1968.

13. Alfenaar, M., "Standard Chemical Free Enthalpy, Enthalpy, Entropy and Heat Capacity of Hydration of the Hydrogen Ion at $25^{\circ} \mathrm{C}$ ", Chemistry Department, University of Oregon, Eugene, Oregon, April 9, 1968.

14. Bates, R.G., "Acid-Base Interactions in Alcohol-Water Media", Maryland Section, American Chemical Society, Towson, Maryland, April 17, 1968.

15. Bates, R.G., "Meaning and Standardization of $\mathrm{pH}$ Measurements", Undergraduate Research Participation Seminar, University of Maryland, College Park, Maryland, June 26, 1968. 
[1] Electrochemical Analysis; Studies of Acids, Bases, and Salts by Emf, Conductance, Optical, and

Kinetic Methods. July 1965 to June 1966.

(R. G. Bates, Ed.), NBS Technical Note 400 (September 6, 1966).

[2] Electrochemical Analysis Section: Summary of Activities, July 1966 to June 1967.

(R. G. Bates, Ed.), NBS Technical Note 423 (October 1967).

[3] British Standard 1647: Specification for pH Scale, British Standards Institution, Iondon (1961).

[4] Bates, R.G.

Ana1. Chem., 40, 28A (May 1968).

[5] Bronsted, J.N.

Rec. Trav. Chim. Pays-Bas, 42, 718 (1923).

[6] Bates, R.G.

"Medium effects and $\mathrm{pH}$ in nonaqueous solvents".

Chapter in Solute-Solvent Interactions

(J.F. Coetzee and C. D. Ritchie, Eds.).

Marcel Dekker. In press.

[7] Bates, R.G.

Chem. Rev., 42, 1 (1948).

[8] Randles, J.E.B.

Trans. Faraday Soc., 52, 1573 (1956).

[9] Bates, R.G., Pinching, G.D., and Smith, E.R. J. Res. Nat. Bur. Stand., 45, 418 (1950).

[10] Covington, A.K., Paabo, M., Robinson, R.A., and Bates, R.G.

Anal. Chem., 40,700 (1968).

[11] Gary, R., Bates, R.G., and Robinson, R.A. J. Phys. Chem., 68, 3806 (1964).

[12] Gary, R., Bates, R.G., and Robinson, R.A. J. Phys. Chem., 69, 2750 (1965).

[13] Bates, R.G. and Guggenheim, E.A. Pure App1. Chem., 1, 163 (1960). 
[14] Bates, R.G.

J. Amer. Chem. Soc., 70, 1579 (1948).

[15] Bates, R.G. and Pinching, G.D.

J. Amer. Chem. Soc., 71,1274 (1949).

[16] Braude, E.A. and Stern, E.S.

J. Chem. Soc., 1976 (1948).

[17] Bernal, J.D, and Fowler, R.H.

J. Chem. Phys., 1, 515 (1933).

[18] Franks, F. and Ives, D.J.G.

Quart. Rev. (Iondon), 20, 1 (1966).

[19] Kundu, K.K., De, A.I., and Das, M.N. Private communication (1967).

[20] Sager, E.E., Robinson, R.A., and Bates, R.G. J. Res. Nat. Bur. Stand., 68A, 305 (1964).

[21] Paabo, M., Bates, R.G., and Robinson, R.A.

J. Phys. Chem., 70, 247 (1966).

[22] Schindler, P., Robinson, R.A., and Bates, R.G. J. Res. Nat. Bur. Stand, 72A, 141 (1968).

[23] Bass, S.J., Nathan, W.I., Melghan, R.M., and Cole, R.H. J.'Phys.' Chem., 68, 509 (1964).

[24] Bates, R.G.

$\frac{\text { Determination of } \mathrm{pH} \text {, Theory and Practice, Chap. }}{3}$ and 4. John Wiley and Sons, Inc., New York (1964).

[25] Garrels, R.M.

"Ion-sensitive electrodes and individual ion activity coefficients". Chapter 13 in Glass Electrodes for Hydrogen and other Cations ( $G$. Eisenman, Ed.) Marcel Dekker, New York (1967).

[26] Fuoss, R.M.

J. Amer. Chem. Soc., 80, 5059 (1958).

[27] Bates, R.G. and Bower, V.E.

J. Res. Nat. Bur. Stand., 53, 283 (1954).

[28] Oiwa, I.T.

Sc1. Rpts. Tohoku Un1v. [1], 41, 47 (1957). 
[29] Covington, A.K., Robinson, R.A., and Bates, R.G. J. Phys. Chem., 70, 3820 (1966).

[30] Curry, J. and Hugus Jr., Z.Z.

J. Amer. Chem. Soc., 66 651 (1944)。

[31] Glasoe, P.K. and Long, F.A.

$$
\text { J. Phys. Chem., 64, } 188 \text { (1960). }
$$

[32] Cox, R.A.

Progr. Oceanogr., 1, 243 (1963).

[33] Janz, G.J. and Mintyre, J.D.E. J. Electrochem. Soc., 108, 272 (1961).

[34] Prue, J.E. and Sherrington, P.J. Trans. Faraday Soc., 57, 1795 (1961).

[35] Fuoss, R.M.

Proc. Nat. Acad. Sci. U.S., 45, 807 (1959).

[36] Zwanzig, R.W.

J. Chem. Phys., 38, 1603 (1963).

[37] Mezhenni, Ya.F.

Ukr. Khim. Zh., 24, 703 (1958).

[38] Minc, S. and Werblan, $L$.

Rocz. Chem., 40, 1989 (1966).

[39] Jasinski, R.J. and Kirkland, S. Anal. Chem., 39, 1663 (1967). 



\section{PERIODICALS}

JOURNAL OF RESEARCH reports National Bureau of Standards research and development in physics, mathematics, chemistry, and engineering. Comprehensive scientific papers give complete details of the work, including laboratory data, experimental procedures, and theoretical and mathematical analyses. Illustrated with photographs, drawings, and charts.

Published in three sections, available separately:

\section{- Physics and Chemistry}

Papers of interest primarily to scientists working in these fields. This section covers a broad range of physical and chemical research, with major emphasis on standards of physical measurement, fundamental constants, and properties of matter. Issued six times a year. Annual subscription: Domestic, \$5.00; foreign, $\$ 6.00 *$.

\section{Mathematical Sciences}

Studies and compilations designed mainly for the mathematician and theoretical physicist. Topics in mathematical statistics, theory of experiment design, numerical analysis, theoretical physics and chemistry, logical design and programming of computers and computer systems. Short numerical tables. Issued quarterly. Annual subscription: Domestic, $\$ 2.25$; foreign, $\$ 2.75 *$.

\section{- Engineering and Instrumentation}

Reporting results of interest chiefly to the engineer and the applied scientist. This section includes many of the new developments in instrumentation resulting from the Bureau's work in physical measurement, data processing, and development of test methods. It will also cover some of the work in acoustics, applied mechanics, building research, and cryogenic engineering. Issued quarterly. Annual subscription: Domestic, $\$ 2.75$; foreign, $\$ 3.50 *$.

\section{TECHNICAL NEWS BULLETIN}

The best single source of information concerning the Bureau's research, developmental, cooperative and publication activities, this monthly publication is designed for the industry-oriented individual whose daily work involves intimate contact with science and technology-for engineers, chemists, physicists, research managers, product-development managers, and company executives. Annual subscription: Domestic, $\$ 1.50$; foreign, $\$ 2.25 *$.
NONPERIODICALS

Applied Mathematics Series.

Mathematical tables, manuals, and studies.

Building Science Series. Research results, test methods, and performance criteria of building materials, components, systems, and structures.

Handbooks. Recommended codes of engineering and industrial practice (including safety codes) developed in cooperation with interested industries, professional organizations, and regulatory bodies.

Special Publications. Proceedings of NBS conferences, bibliographies, annual reports, wall charts, pamphlets, etc.

Monographs. Major contributions to the technical literature on various subjects related to the Bureau's scientific and technical activities.

National Standard Reference Data Series. NSRDS provides quantitative data on the physical and chemical properties of materials, compiled from the world's literature and critically evaluated.

Product Standards. Provide requirements for sizes, types, quality and methods for testing various industrial products. These standards are developed cooperatively with interested Government and industry groups and provide the basis for common understanding of product characteristics for both buyers and sellers. Their use is voluntary.

Technical Notes. This series consists of communications and reports (covering both other agency and NBS-sponsored work) of limited or transitory interest.

\section{CLEARINGHOUSE}

The Clearinghouse for Federal Scientific and Technical Information, operated by NBS, supplies unclassified information related to Governmentgenerated science and technology in defense, space, atomic energy, and other national programs. For further information on Clearinghouse services, write:

Clearinghouse

U.S. Department of Commerce Springfield, Virginia 22151

Order NBS publications from:

Superintendent of Documents

Government Printing Office

Washington, D.C. 20402 
U.S. DEPARTMENT OF COMMERCE WASHINGTON, D.C. 20230

OFFICIAL BUSINESS 